NASA Technical Memorandum 4682

\title{
Stress and Damage in Polymer Matrix Composite Materials Due to Material Degradation at High Temperatures
}

Hugh L. McManus and Christos C. Chamis

JANUARY 1996

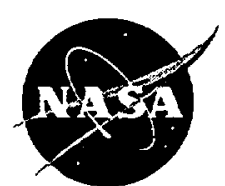

National Aeronautics and

Space Administration 

NASA Technical Memorandum 4682

\section{Stress and Damage in Polymer Matrix Composite Materials Due to Material Degradation at High Temperatures}

Hugh L. McManus

Massachusetts Institute of Technology

Cambridge, Massachusetts

Christos C. Chamis

Lewis Research Center

Cleveland, Ohio

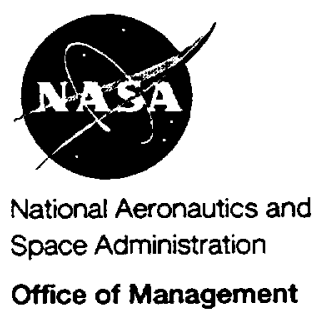

Scientific and Technical Information Program 


\title{
STRESS AND DAMAGE IN POLYMER MATRIX COMPOSITE MATERIALS DUE TO MATERIAL DEGRADATION AT HIGH TEMPERATURES
}

\author{
Hugh L. McManus* \\ Massachusetts Institute of Technology \\ Cambridge, MA 02139 \\ and \\ Christos C. Chamis \\ National Aeronautics and Space Administration \\ Lewis Research Center \\ Cleveland, $\mathrm{OH} 44135$
}

\section{Summary}

This report describes analytical methods for calculating stresses and damage caused by degradation of the matrix constituent in polymer matrix composite materials. Laminate geometry, material properties, and matrix degradation states are specified as functions of position and time. Matrix shrinkage and property changes are modeled as functions of the degradation states. The model is incorporated into an existing composite mechanics computer code. Stresses, strains, and deformations at the laminate, ply, and micro levels are calculated, and from these calculations it is determined if there is failure of any kind. The rationale for the model (based on published experimental work) is presented, its integration into the laminate analysis code is outlined, and example results are given, with comparisons to existing material and structural data. The mechanisms behind the changes in properties and in surface cracking during long-term aging of polyimide matrix composites are clarified. High-temperature-material test methods are also evaluated.

\subsection{Introduction}

Polymer matrix composite materials are increasingly being used for moderately high-temperature $\left(200\right.$ to $\left.350^{\circ} \mathrm{C}\right)$ applications. These applications do not have extreme temperature requirements, but still involve service temperatures well above the capabilities of typical epoxy matrices in current aerospace use. Advanced polyimide matrices have been formulated for service at these temperatures, and composites employing these matrices are already in use in engine cowls, ducts, thrust reversers, and such. These composites have been identified as an enabling technology for advancements in turbine engines, hot aircraft structures, and high-speed aircraft structures. How- ever, a critical problem preventing more widespread use of these materials is the aging and degradation of the matrix. Continuous exposure to high temperatures has been shown to cause mass loss, degradation of properties, shrinkage, and cracking. Our inability to quantify matrix degradation and its effect on composite properties and behavior is a limiting factor in the application of composite materials to these problems.

A better understanding of the degradation of hightemperature polymeric composite materials is essential. Obviously, degradation is a complex and coupled process: heat, moisture, and oxygen are transported into the material; the matrix material changes chemically; the changes in the matrix affect the behavior of the composite material at the ply and laminate level; and this behavior sometimes leads to cracking or other failures. Failures such as matrix cracks may in turn lead to greatly enhanced oxygen ingress, greater material changes, and more cracking - clearly a coupled, and potentially unstable, situation. We need to be able to analytically model this problem. Testing is also required, but it cannot be pursued blindly. There must be an understanding of what a given test is measuring. Even without a full set of material property data, analytical tools can aid in the identification of critical phenomena, the design of tests, and the interpretation of test results. Coupled with experimentally collected material property data, analytical tools will ultimately provide design capability for durable high-temperature composite structures.

The work presented here concentrates on a current weak point in analytical capability-linking matrix material degradation and shrinkage to the ply and laminate behavior that results. The objective of this report is to describe a new set of analytical methods that can be used to predict the effects of matrix degradation and shrinkage on the performance of composite laminates. 


\subsection{Background}

Extensive testing has been carried out to characterize the performance of polymer matrix composites at high temperatures. This report will concentrate on the most commonly used material systems, the NASA-Lewis-developed polymer monomeric reactant (PMR) polyimide materials. Other materials, notably other polyimide thermosets and thermoplastic materials such as PEEK, have also been included in aging studies. Many of the phenomena observed are similar to those reported for PMR materials. Recent developments in the PMR material system are discussed in reference 1. Most testing has concentrated on isothermal aging, that is, the effects of continuous soaking at a single high temperature (refs. 2 to 10 ).

Exposing PMR matrix materials to high temperatures for moderate lengths of time (hundreds of hours) first leads to increases in the glass transition temperature $T_{g}$. This change is thought to be due to additional chemical cross-linking in the matrix. In the presence of air, oxidation may speed this process (ref. 2). Other changes include increases in the material's stiffness, bending strength, and shear strength, when these properties are measured at the exposure temperature. When they are measured at room temperature, these properties, as well as interlaminar fracture toughness, decrease (refs. 3 and 4). The viscoelastic behavior is also affected since compliance decreases with exposure time (ref. 5 ).

At the upper end of the temperature range or at longer exposure times, severe mass loss is also noted. Although fibers can lose mass, the mass loss in the composite is predominantly matrix mass loss (ref. 6 ) that is caused by oxygen cutting up the polymer and ultimately destroying it. In nonreactive atmospheres, mass loss is reduced but not entirely eliminated (ref. 2). Mass loss is associated with notable shrinkage of the material and a decline in the values of the material's properties. The degradation begins at exposed surfaces, where a distinct degraded layer is observed in both neat resin specimens and composites (ref. 7). As aging continues, the degraded layer grows. This process is thought to be controlled by the rate of oxygen diffusion into the material (R.C. Hipp, D.M. Harmon, and P.S. McClellan, 1994, MacDonnell Douglas Co., unpublished data).

Eventually, voids and cracks form in the degraded region. Cracks allow oxygen to penetrate deeper into the material, thereby accelerating the degradation process (ref. 7). Bowles (K.J. Bowles, NASA Lewis Research Center, unpublished data) suggested that in extreme cases an interconnected network of microcracks eventually forms, which allows extensive oxidation throughout the laminate and causes the composite to become completely ineffective.

Attempts have been made to analyze and model various aspects of this problem. Mass-loss rates have been empirically fitted to Arrhenius rate curves (M.A. Grayson and C.G. Fry, 1994, MacDonnell Douglas Co., unpublished data). More sophisticated models have combined modeling of oxygen diffusion into the material with the chemical reaction rate equations to predict mass loss and the growth of degraded layers (R.C. Hipp, D.M. Harmon, and P.S. McClellan, 1994, MacDonnell Douglas Co., unpublished data). Cracking of these degraded layers has been predicted by a finite element model (ref. 4) that treated the degraded layers as layers with different material properties. In addition, changes in viscoelastic properties have been incorporated into standard viscoelastic analysis techniques (ref. 5).

More general analysis techniques that can be applied to some aspects of this problem are also available. Although there are many such techniques, here only those used in this work are presented. Given the matrix and fiber properties (ref. 11), existing micromechanical models can predict composite properties and behavior. The effects of temperature and moisture on composite properties can also be predicted (refs. 12 and 13). Perhaps existing semi-empirical analysis methods for composite durability (ref. 14) could be applied to this problem. Success, however, is unlikely, since these methods do not account for the unique physics observed in the high-temperature degradation process.

No current analysis technique can predict the properties of, and stresses in, a general composite laminate undergoing high-temperature degradation. Changes in matrix properties, mass loss, shrinkage and void formation-and the uneven distribution of these degradation effects-all must be accounted for in such an analysis.

\subsection{Statement of Problem}

Given the geometry of a laminate, the applied mechanical loads, the constituent material properties, and the temperature, moisture, and matrix degradation states for each ply in the laminate, we must find the stresses, strains, and deformations at the laminate, ply, and microstructural levels, and determine if any failures occur. Once this capability is achieved and added to an existing composite analysis package, we must verify it by comparing the results to existing experimental data.

\subsection{Approach}

The problem is approached herein in three steps:

(1) Based on existing experimental evidence, an empirical model is developed in which shrinkage and changes in matrix properties are functions of several different degradation mechanisms.

(2) From fundamental micromechanics principles, the effects that these changes in the matrix will have on unidirectional plies is predicted. 
(3) By using modified classical-laminated-plate relations, the effect of ply changes on laminate behavior is predicted.

These three models are then used to calculate stresses due to degradation and mechanical and hygrothermal loading at the laminate, ply, and micromechanical levels. Composite failure criteria are used to determine if failures occur.

\subsection{Matrix Degradation Modeling}

\subsection{Empirical Basis}

A quantitative and computationally useful model of the matrix shrinkage and the changes in material properties caused by degradation was constructed. It was based on information obtained in the current literature and in extensive discussions with the materials communities at NASA's Lewis and Langley Research Centers. The matrix was modeled as undergoing two time-dependent processes, and the fibers were assumed to be stable. All symbols used herein are defined in appendix $\mathrm{A}$.

The first process is a matrix mechanism that is partly an extension of the cure process, in which the matrix changes by chemical and physical aging. This mechanism, which depends on temperature and time, is associated with small amounts of matrix shrinkage and mass loss (less than 1 percent) and with density and material property changes. In thermoset materials, this mechanism is dominated by changes in chemical cross-linking, so the mechanism will be referred to here as the cross-linking mechanism.

The second process is a degradation mechanism due to oxidation and/or another mechanism that breaks down the polymer structure of the matrix. Temperature and oxygen availability govern this mechanism. In thick parts of the matrix, this mechanism appears to be diffusion limited and, thus, occurs mostly on the surface, causing material property changes (mostly degradations) and mass loss. Mass can be lost by erosion of the surface (making the part smaller), formation of voids, reduction in density of the matrix, or shrinkage of the matrix. In practice, density changes are not observed, whereas some void formation and major shrinkage are observed (ref. 5). This second mechanism will be referred to as the mass-loss mechanism.

\subsection{Degradation Metrics}

The degradation state at a point will be represented by two dimensionless metrics: $a$, the cross-linking mechanism; and $b$, the mass-loss mechanism. The first, $a$, is a measure of chemical cross-linking and is taken to be proportional to the increase in the measured glass transition temperature of the matrix material. The second, $b$, is a measure of the breakdown of the polymer and is taken to be proportional to mass loss.
The metrics are defined such that they have the value 0 in virgin material and 1 in fully degraded material. They are defined as follows:

$$
\begin{gathered}
a=\frac{T_{g}-T_{g o}}{T_{g f}-T_{g o}} \\
b=\frac{m_{o}-m}{m_{o}}
\end{gathered}
$$

where $T_{g}$ is the measured glass transition temperature, $m$ is the mass in a small volume of matrix surrounding the point at which the degradation is specified, and the subscripts $o$ and $f$ represent the initial and final states. Note that $a$ is positive for an increase in $T_{g}$, whereas $b$ is positive for a decrease in mass; the final state in the mass-loss case occurs when the mass is zero. These metrics specify the degradation state at a single point and at a given time. However, because the degradation state within a specimen is time dependent and nonuniform, these metrics must be specified as functions of time and position.

\subsection{Matrix Property Changes}

The effects of aging on the matrix's room temperature properties are modeled empirically as functions of the two degradation metrics. The intent of these models is not to predict property changes, but to reduce the existing data to a computationally convenient form. The engineering stiffness properties $E_{m}$ and $G_{m}$ of the matrix are altered by aging as follows:

$$
P_{R T}=P_{R T o} \cdot\left[1+\Delta E_{a}(a)^{n} E a\right] \cdot\left[1+\Delta E_{b}(b)^{n}{ }_{E b}\right]
$$

where $P_{R T}$ represents the modified property used in all subsequent calculations, $P_{R T o}$ represents the initial value of that property, and $\Delta E_{a}$ and $\Delta E_{b}$ represent changes in $E_{m}$ associated with the first and second mechanisms respectively. The Poisson's ratio is assumed to be unaffected, and $\Delta E$ and $n_{E}$ are determined by fitting equation (3) to available data for each reaction. The additional subscripts $a$ and $b$ refer to the reaction type defined above.

Similarly, the room temperature matrix strengths in tension, compression, and shear $\left(S_{m T} S_{m C}, S_{m S}\right)$ are modified as follows:

$$
P_{R T}=P_{R T o} \cdot\left[1+\Delta S_{a}(a)^{n} S a\right] \cdot\left[1+\Delta S_{b}(b)^{n_{s b}}\right]
$$

And the matrix thermal expansion coefficient $\alpha_{m}$ is modified by 


$$
P_{R T}=P_{R T o} \cdot\left[1+\Delta \alpha_{a}(a)^{n}{ }_{\alpha a}\right] \cdot\left[1+\Delta \alpha_{b}(b)^{n_{\alpha b}}\right]
$$

where again $\Delta S, \Delta \alpha, n_{S}$, and $n_{a}$ are fit to available data.

The effects of temperature on matrix properties are modeled by using an existing empirical relation (ref. 12). Strength and stiffness properties at temperature $T$ are

$$
P(T)=P_{R T} \cdot\left(\frac{T_{g}-T}{T_{8}-T_{R T}}\right)^{1 / 2}
$$

where $T_{R T}$ is room temperature. Thermal expansion coefficients are also modified by equation (6), but with the $1 / 2$ power replaced by $-1 / 2$ (from ref. 12). Degraded properties at temperature $T$ are found by first applying equations (3) to (5) and then applying equation (6).

\subsection{Shrinkage and Void Formation}

Consider an infinitesimal cube of matrix material (fig. 1) with initial side length $l_{o}$ and porosity $\phi_{o}$. The cube is unrestrained and effectively homogeneous, with the porosity uniformly distributed. The solid material (not including voids) within this cube has volume $V_{o}$, density $\rho_{o}$, and mass $m_{o}$. The volume of matrix material in the cube is then

$$
V_{o}=\left(1-\phi_{o}\right) l_{o}^{3}
$$

and its mass is

$$
m_{o}=\rho_{o}\left(1-\phi_{o}\right) l_{o}^{3}
$$

In response to degradation, the volume can (1) lose mass, which gives a new mass $m$; (2) shrink, which results in a new side dimension $l$; (3) develop voids (increase porosity), which yields a new porosity $\phi$; and (4) change density, which results in a new density $\rho$. The new volume and mass are thus

$$
\begin{gathered}
V=(1-\phi) l^{3} \\
m=\rho(1-\phi) l^{3}
\end{gathered}
$$

A matrix shrinkage strain $\varepsilon_{m}^{*}$ is defined as follows for a small strain:

$$
\varepsilon_{m}^{*}=\frac{\left(l-l_{o}\right)}{l_{o}}
$$

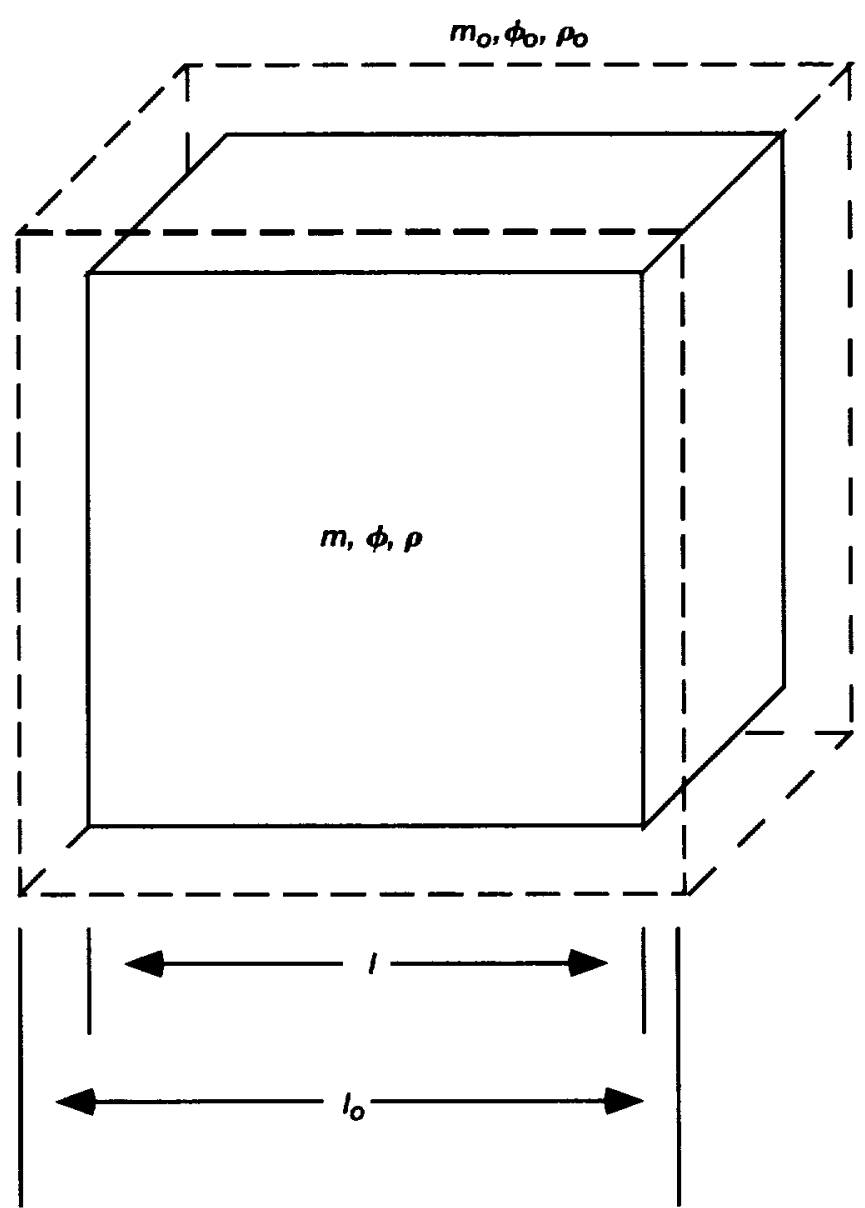

Figure 1.-Cube of matrix material undergoing shrinkage, mass loss, and changes in porosity and density.

or

$$
l=l_{o}\left(1-\varepsilon_{m}^{*}\right)
$$

Combining equations (8) and (10)

$$
\frac{m}{m_{o}}=\frac{\rho}{\rho_{o}} \frac{(1-\phi) l^{3}}{\left(1-\phi_{o}\right) l_{o}^{3}}
$$

and substituting equation (12) into equation (13) gives

$$
\frac{m}{m_{o}}=\frac{\rho}{\rho_{o}} \frac{(1-\phi)}{\left(1-\phi_{o}\right)}\left(1+\varepsilon_{m}^{*}\right)^{3}
$$

Assuming small strains and discarding higher order terms in strain reduces equation (14) to 


$$
\frac{m}{m_{o}}=\frac{\rho}{\rho_{o}} \frac{(1-\phi)}{\left(1-\phi_{o}\right)}\left(1+3 \varepsilon_{m}^{*}\right)
$$

As discussed previously, degradation is assumed to consist of two primary mechanisms, both of which can result in shrinkage of the matrix. The shrinkage due to cross-linking is designated $\varepsilon_{a}^{*}$, and the shrinkage due to mass loss is $\varepsilon_{b}^{*}$. Thus

$$
\varepsilon_{m}^{*}=\varepsilon_{a}^{*}+\varepsilon_{b}^{*}
$$

\subsection{Shrinkage Due to Cross-Linking}

The cross-linking mechanism is assumed to cause no mass loss or change in porosity. The matrix shrinkage due to crosslinking, if any, can be measured experimentally and fit to the following empirical relation:

$$
\varepsilon_{a}^{*}=-C a^{n}
$$

where $C$ and $n$ are fit to data. In the absence of mass loss, porosity growth, and mass-loss-related shrinkage, equation (15) requires that

$$
\rho=\frac{\rho_{o}}{\left(1+3 \varepsilon_{a}^{*}\right)}
$$

\subsection{Shrinkage Due to Mass Loss}

The mass-loss mechanism is assumed to cause matrix shrinkage and increased porosity. Limited experimental evidence (ref. 15) indicates the remaining material has constant density. If we assume constant density, and no shrinkage due to cross-linking, equation (15) can be expanded to

$$
\frac{m}{m_{o}}=\frac{\left(1+\varepsilon_{b}^{*}-\phi-3 \phi \varepsilon_{b}^{*}\right)}{\left(1-\phi_{o}\right)}
$$

Combining equations (2) and (19) and rearranging yields

$$
b=\frac{\left(3 \varepsilon_{b}^{*}+\phi-\phi_{o}+3 \phi \varepsilon_{b}^{*}\right)}{\left(1-\phi_{o}\right)}
$$

Expanding equation (20) as a Taylor series about $\phi_{o}=0$ and eliminating higher order terms in $\phi, \phi_{o}$, and $\varepsilon_{b}^{*}$ (which are assumed to be small) yields

$$
b=-3 \varepsilon_{b}^{*}+\phi-\phi_{O}
$$

The fraction of mass loss due to changes in porosity is defined as an empirical parameter $D$. It can be determined by fitting to data from appropriate experiments. In terms of equation (21)

$$
D=\frac{\phi-\phi_{o}}{-3 \varepsilon_{b}^{*}+\phi-\phi_{o}}
$$

The rest of the mass loss must be accounted for by shrinkage. Combining equations (21) and (22), and rearranging to express shrinkage and porosity changes, yields both

$$
\varepsilon_{b}^{*}=-\frac{(1-D) b}{3}
$$

and

$$
\phi=\phi_{o}+D b
$$

\subsection{Effects at the Ply Level}

\subsection{Volume Fractions}

Consider a composite with an initial matrix volume fraction $k_{m o}$, an initial void volume fraction $k_{v o}$, and an unchanging fiber volume fraction $k_{f}$ The effects of degradation on the volume fractions are calculated here. By definition,

$$
k_{f}+k_{m o}+k_{v o}=1
$$

If we assume that the voids are only in the matrix, the matrix porosity used in the previous section can be defined as

$$
\phi_{o}=\frac{k_{v o}}{k_{v o}+k_{m o}}
$$

From equations (25) and (26)

$$
k_{v o}=\left(1-k_{f}\right) \phi_{o}
$$

and

$$
k_{m o}=\left(1-k_{f}\right)\left(1-\phi_{o}\right)
$$

Similarly,

$$
k_{v}=\left(1-k_{f}\right) \phi
$$

and

$$
k_{m}=\left(1-k_{f}\right)(1-\phi)
$$


Combining equations (24), (27), and (29) yields the modified void volume fraction $k_{v}$ :

$$
k_{v}=k_{v o}+\left(1-k_{f}\right) D b
$$

And combining equations (24), (28), and (30) yields the modified matrix volume fraction $k_{m}$ :

$$
k_{m}=k_{m o}-\left(1-k_{f}\right) D b
$$

\subsection{Ply Properties}

Ply properties are calculated from the fiber properties and the matrix properties as modified by aging (see eqs. (3) to (6)). The micromechanical relations of reference 12 are used. In the notation of reference 12 , the subscripts $l, m$, and $f$ denote a ply property, a matrix property, and a fiber property, respectively. Numerical subscripts refer to directions as shown in figure 2 . The relations are repeated here for convenience:

$$
\begin{gathered}
E_{\ell 11}=k_{f} E_{f 11}+k_{m} E_{m} \\
E_{\ell 22}=E_{\ell 33}=\frac{E_{m}}{1-\sqrt{k_{f}}\left(1-E_{m} / E_{f 22}\right)} \\
G_{\ell 12}=\mathrm{G}_{\ell 13}=\frac{G_{m}}{1-\sqrt{k_{f}}\left(1-G_{m} / G_{f 12}\right)} \\
G_{\ell 23}=\frac{G_{m}}{1-\sqrt{k_{f}}\left(1-G_{m} / G_{f 23}\right)}
\end{gathered}
$$

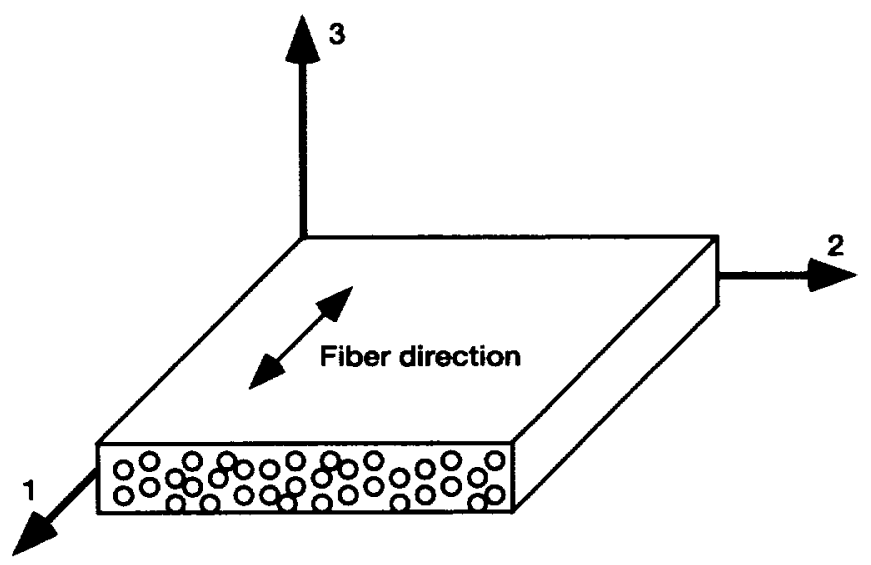

Figure 2.-Ply coordinate system.

$$
\begin{gathered}
v_{\ell 12}=v_{\ell 13}=k_{f} v_{f 12}+k_{m} v_{m} \\
v_{\ell 23}=\frac{E_{\ell 22}}{2 G_{\ell 23}}-1
\end{gathered}
$$

$$
\alpha_{\ell 11}=\frac{k_{f} \alpha_{f 11} E_{f 11}+k_{m} \alpha_{m} E_{m}}{E_{\ell 11}}
$$

$$
\alpha_{\ell 22}=\alpha_{\ell 33}=\alpha_{f 22} \sqrt{k_{f}}+\left(1-\sqrt{k_{f}}\right)\left(1+\frac{k_{f} v_{m} E_{f 11}}{E_{\ell 11}}\right) \alpha_{m}
$$

\subsection{Ply Shrinkage}

The matrix shrinkage associated with degradation causes deformations at the ply level. The fibers are assumed to be dimensionally stable, and hence restrain the shrinking of the matrix. This behavior is analogous to the thermal expansion of a ply consisting of a fiber and a matrix with different thermal expansion coefficients. It results in a ply deformation that is intermediate between the deformation of unrestrained matrix material and the zero deformation of bare fiber, as shown in figure 3. Micromechanical relations must be used to determine the net ply-level deformations and the residual stresses in the fibers and matrix.

The micromechanical relations are analogous to those used to determine the ply thermal expansion coefficients. They are derived by modifying the micromechanics of reference 12 . Matrix shrinkage coefficients $\zeta_{m}$ and $\chi_{m}$ are defined for the

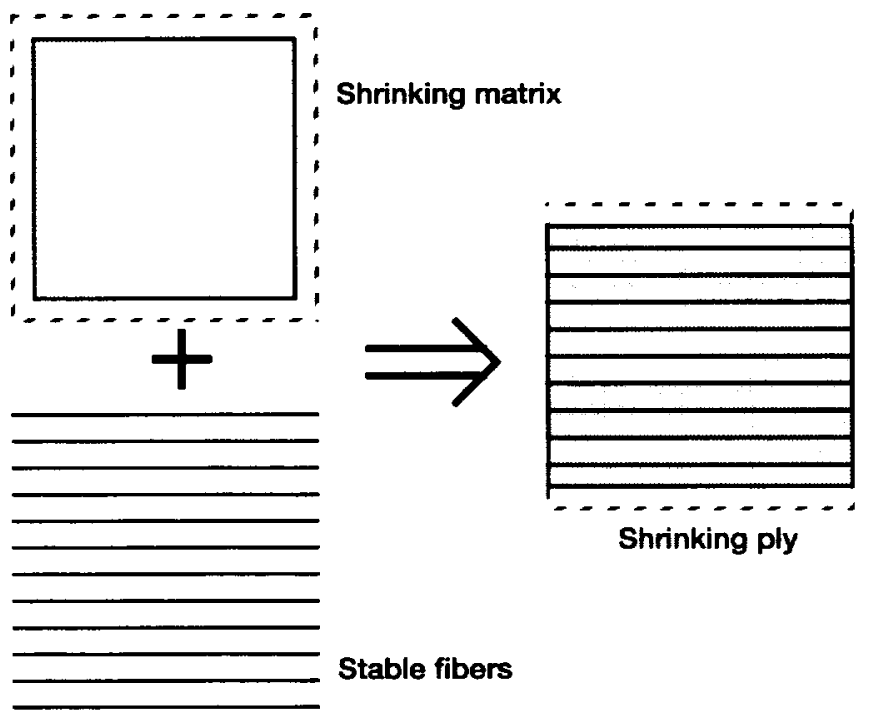

Figure 3.-Micromechanics of ply shrinkage. 
cross-linking and mass-loss mechanisms, respectively, such that

$$
\begin{aligned}
& \varepsilon_{a}^{*}=\zeta_{m} a \\
& \varepsilon_{b}^{*}=\chi_{m} b
\end{aligned}
$$

hence

$$
\begin{gathered}
\zeta_{m}=\frac{\varepsilon_{b}^{*}}{a} \\
\chi_{m}=\frac{\varepsilon_{b}^{*}}{b}
\end{gathered}
$$

Combining equations (17) and (43) yields

$$
\zeta_{m}=-C a^{(n-1)}
$$

For $n=1$, which implies a linear relationship between shrinkage and this degradation mechanism,

$$
\zeta_{m}=-C
$$

Combining equations (23) and (44) gives

$$
\chi_{m}=-\frac{(1-D)}{3}
$$

The fibers are assumed to be stable, so all fiber shrinkage coefficients are zero; thus

$$
\zeta_{f 11}=\zeta_{f 22}=\zeta_{f 22}=\chi_{f 11}=\chi_{f 22}=\chi_{f 33}=0
$$

where the subscripts are defined in the same fashion as for the thermal expansion coefficients (eqs. (39) and (40)).

The micromechanics of this problem are identical to those of the thermal expansion of a composite consisting of fiber and matrix with different thermal expansion coefficients. Relations for the shrinkage coefficients of the plies can thus be developed in the same way as those for ply thermal expansion coefficients. This subject is well covered in the literature, so the development will not be repeated here. Instead, by direct analogy to equations (39) and (40), the ply degradation coefficients are written as

$$
\begin{gathered}
\zeta_{\ell 11}=\frac{k_{m} E_{m}}{E_{\ell 11}} \zeta_{m} \\
\zeta_{\ell 22}=\zeta_{\ell 33}=\left(1-\sqrt{k_{f}}\right)\left(1+\frac{k_{f} v_{m} E_{\ell 11}}{E_{\ell 11}}\right) \zeta_{m}
\end{gathered}
$$

$$
\begin{gathered}
\chi_{\ell 11}=\frac{k_{m} E_{m}}{E_{\ell 11}} \chi_{m} \\
\chi_{\ell 22}=\chi_{\ell 33}=\left(1-\sqrt{k_{f}}\right)\left(1+\frac{k_{f} v_{m} E_{\ell 11}}{E_{\ell 11}}\right) \chi_{m}
\end{gathered}
$$

For $n=1$, equation (46) can be combined with equations (48) and (49) to yield

$$
\zeta_{\ell 11}=\frac{k_{m} E_{m}}{E_{\ell 11}} C
$$

and

$$
\zeta_{\ell 22}=\zeta_{\ell 33}=-\left(1-\sqrt{k_{f}}\right)\left(1+\frac{k_{f} v_{m} E_{f 11}}{E_{\ell 11}}\right) C
$$

Similarly, equation (47) can be combined with equations (50) and (51) to yield

$$
\chi_{\ell 11}=-\frac{k_{f} E_{m}}{E_{\ell 11}}\left[\frac{(1-D)}{3}\right]
$$

$\chi_{\ell 22}=\chi_{\ell 33}=-\left(1-\sqrt{k_{f}}\right)\left(1+\frac{k_{f} v_{m} E_{f 11}}{E_{\ell 11}}\right) \frac{(1-D)}{3}$

The in-plane ply shrinkage strains due to degradation, $\varepsilon_{\ell 11}^{*}$ and $\varepsilon_{\ell 22}^{*}$, can now be calculated as

$$
\begin{aligned}
& \varepsilon_{\ell 11}^{*}=\zeta_{\ell 11} a+\chi_{\ell 11} b \\
& \varepsilon_{\ell 22}^{*}=\zeta_{\ell 22} a+\chi_{\ell 22} b
\end{aligned}
$$

\subsection{Microstresses}

The mismatch between the shrinkage of the matrix and the fibers creates stresses at the micro scale, even in plies that are stress-free at the ply level. By modifying the relations of reference 13 , the microstresses due solely to the degradation effects can be calculated as follows;

$$
\begin{gathered}
\sigma_{m 11}=\left(\varepsilon_{\ell 11}^{*}-\varepsilon_{m}^{*}\right) E_{m} \\
\sigma_{f 11}=E_{f 11} \varepsilon_{\ell 11}^{*}
\end{gathered}
$$




$$
\begin{gathered}
\sigma_{m 22 A}=\left(\varepsilon_{\ell 22}^{*}-\varepsilon_{m}^{*}\right) E_{m} \\
\sigma_{m 22 B}=-\frac{1-\sqrt{k_{f}}}{\sqrt{k_{f}}} \sigma_{m 22 A} \\
\sigma_{f 22}=\sigma_{m 22 B} \\
\sigma_{m 33 A}=\sigma_{m 22 A} \\
\sigma_{m 33 B}=\sigma_{m 22 B} \\
\sigma_{f 33}=\sigma_{f 22}
\end{gathered}
$$

where $f$ indicates stress in the fibers; $m$, stress in the matrix; and $A$ and $B$, different regions within the matrix (see ref. 13 for a complete description of this scheme).

\subsection{Effects at the Laminate Level}

\subsection{Laminate Theory}

Property changes and shrinkage effects at the laminate level are calculated by using the modified Classical Laminated Plate Theory (CLPT) (K.J. Bowles, NASA Lewis Research Center, personal correspondence). Laminate properties are calculated according to the relations in appendix B, with the altered ply properties. The effects of shrinkage on the laminate are analogous to those caused by thermal deformations. A modification of CLPT is used to define and apply effective in-plane and bending degradation forces to the laminate. Next, laminate deformations are calculated, and then ply stresses are calculated from the deformed laminate shape.

The shrinkage strain for each ply $i$, with ply angle $\theta_{i}$, are expressed in compact form as

$$
\varepsilon_{\ell(i)}^{*}=\left\{\begin{array}{c}
\varepsilon_{\ell 11}^{*} \\
\varepsilon_{\ell 22}^{*} \\
0
\end{array}\right\}_{i}
$$

The shrinkage strains in the laminate coordinate system are

$$
\bar{\varepsilon}_{\ell(i)}^{*}=\mathbf{T}_{i}^{-\top} \varepsilon_{\ell(i)}^{*}
$$

where $\mathbf{T}_{i}$ is the transform matrix defined in appendix $\mathrm{B}, \mathrm{T}$ indicates matrix transpose, and $-T$ indicates inverse transpose. The laminate response, effective forces, and moments are cal-culated and applied in calculations analogous to those used in calculating thermal responses. The effective forces and moments on a laminate with $N$ plies, $\mathbf{N}^{*}$ and $\mathbf{M}^{*}$ respectively, are

$$
\mathbf{N}^{*}=\sum_{i=1}^{N} \overline{\mathbf{Q}}_{i} \bar{\varepsilon}_{\ell(i)}^{*}\left(z_{i}^{t}-z_{i}^{b}\right)
$$

and

$$
\mathbf{M}^{*}=\frac{1}{2} \sum_{i=1}^{N} \overline{\mathbf{Q}}_{i} \bar{\varepsilon}_{\ell(i)}^{*}\left[\left(z_{i}^{t}\right)^{2}-\left(z_{i}^{b}\right)^{2}\right]
$$

Here $z_{i}^{t}$ and $z_{i}^{b}$ represent the distance from the top and bottom, respectively, of ply $i$ to the laminate centerline, and $\bar{Q}_{i}$ is the rotated reduced stiffness matrix of the ply, the calculation of which is described in appendix $B$. The total laminate strains and curvatures, including mechanical, thermal, and hygral effects are

$$
\begin{aligned}
& \varepsilon_{o}=\mathrm{a}\left(\mathbf{N}+\mathbf{N}^{T}+\mathbf{N}^{H}+\mathbf{N}^{*}\right)+\mathrm{b}\left(\mathbf{M}+\mathbf{M}^{T}+\mathbf{M}^{H}+\mathbf{M}^{*}\right) \\
& \kappa=\mathrm{b}^{T}\left(\mathrm{~N}+\mathrm{N}^{T}+\mathrm{N}^{H}+\mathrm{N}^{*}\right)+\mathrm{d}\left(\mathbf{M}+\mathrm{M}^{T}+\mathrm{M}^{H}+\mathrm{M}^{*}\right)
\end{aligned}
$$

The $\mathbf{a}, \mathbf{b}$, and $\mathbf{d}$ matrices are the inverse laminate stiffness matrices, calculated according to the relations given in appendix B. The midplane strains $\bar{\varepsilon}_{\ell(i)}$ in each layer are

$$
\bar{\varepsilon}_{\ell(i)}=\varepsilon_{o}+\kappa z_{i}
$$

where $z_{i}$ is the distance from the midplane of ply $i$ to the laminate midplane. The stresses in the laminate coordinate system are then

$$
\bar{\sigma}_{\ell(i)}=\overline{\mathbf{Q}}_{i}\left(\bar{\varepsilon}_{\ell(i)}+\bar{\varepsilon}_{\ell(i)}^{T}+\bar{\varepsilon}_{\ell(i)}^{H}+\bar{\varepsilon}_{\ell(i)}^{*}\right)
$$

where $\bar{\varepsilon}_{\ell}^{T}$ is the ply free thermal strain in the laminate coordinate system and $\bar{\varepsilon}_{\ell}^{H}$ is the ply free hygral strain in the laminate coordinate system. In the ply coordinate system

$$
\left\{\begin{array}{l}
\sigma_{\ell 11} \\
\sigma_{\ell 22} \\
\sigma_{\ell 12}
\end{array}\right\}_{i}=\mathbf{T}_{i} \bar{\sigma}_{\ell(i)}
$$




\subsection{Ply Failure}

The maximum stress failure criterion ratios for longitudinal, transverse, and shear stress in each ply are calculated in this section:

$$
\begin{array}{cc}
R_{l}= & \sigma_{\ell 11} \geq 0 \\
\frac{-\sigma_{\ell 11}}{S_{\ell 11 C}} & \sigma_{\ell 11}<0 \\
R_{t}= & \sigma_{\ell 22} \geq 0 \\
\frac{\sigma_{\ell 22}}{S_{\ell 22 T}} & \sigma_{\ell 22}<0 \\
\frac{-\sigma_{\ell 22}}{S_{\ell 22 C}} & \\
R_{s}=\frac{\sigma_{\ell 12}}{S_{\ell 12 S}} &
\end{array}
$$

If $R_{i}>1.0$, the ply has failed in mode $i$.

The ultimate tensile and compressive strengths ( $T$ and $C$ subscripts) in the fiber direction and transverse direction (11 and 22 subscripts) and the ultimate shear strength $S_{\ell 12 S}$ are all calculated at the moisture, temperature, and degradation conditions of the ply. This is done by using existing microstructural relations (ref. 12) and matrix constitutive properties as modified by equations (4) and (6).

\subsection{Implementation}

\subsection{Computer Code}

The method just outlined for calculating laminate deformations, ply stresses, and microstresses is implemented as a module of the ICAN computer code. A complete description of this code is given in reference 11. The user specifies laminate geometry, loadings, temperatures, moisture contents, and degradation states. A typical input file is shown in appendix $C$. The user can also modify a material data base file containing constituent material properties and the constants relating degradation to material property changes. An example data base, containing properties for both the C-6000 fiber and the PMR-15 matrix, is given in appendix D. The code output is illustrated in appendix E. A useful spinoff of this work has been the creation of an easy-to-use Macintosh version of the ICAN code.

\subsection{Material Data Base}

The existing ICAN data base was updated with properties for the C-6000 fiber and modified properties for the PMR-15 matrix material. The fiber properties were taken from reference 8; unavailable properties were scaled from the existing data base for the similar AS4 fibers. The existing PMR-15 data base was modified as follows: (1) the shear strength was increased to reflect the ratio of shear strength to the ultimate tensile strength observed for virtually all resin materials; (2) the initial value of $T_{g}$ was updated (ref. 2); and (3) degradation material constants were added. Cross-linking was assumed to cause no material property changes other than those due to an increase in $T_{g}$ (which are extensive at high temperatures), and to cause no shrinkage or density change. Mass loss was, as a conservative baseline, assumed to cause only shrinkage (no void formation). This assumption contradicts some available evidence (ref. 7), so the percentage of mass loss due to void formation was later studied parametrically. The effective properties of the material were assumed to decrease in linear proportion to mass loss. This is consistent with assuming that the remaining material has unchanged material properties, which is supported by a small amount of evidence (ref. 15). The baseline data used are found in appendix D.

\subsection{Verification and Example Uses}

The code was exercised to verify that its predictions could correlate with experimentally observed results. Two verification correlations were performed: (1) Predictions of changes in the high-temperature properties of PMR matrix composites were made on the basis of assumed cross-linking and then were correlated with available data. (2) Predictions of gross sample shrinkage were made by using the data on mass loss and growth of a surface degradation zone with the mass loss degradation model, and the predictions were correlated with available data. The verified code was then used to reach a better understanding of (1) the causes of cracking in unloaded specimens, (2) the response of aged specimens undergoing longitudinal bending tests, and (3) the response of aged specimens undergoing transverse bending tests.

\subsection{Cross-Linking Correlation}

The bending and shear strengths of a unidirectional sample were predicted at various temperatures as functions of the cross-linking metric $a$. The results were correlated with the data of Bowles (ref. 9) and Vannucci and Cifani (ref. 2). Room temperature results from both authors were used, but only the after-aging results from Bowles were used. He aged his specimens in nitrogen; Vannucci and Cifani aged theirs in air, so their results are complicated by surface degradation 
effects. The parameter $T_{g f}$ in equation (1), defined as the glass transition temperature of a fully cross-linked matrix, was not available in the literature. In fact, it was noted in reference 9 that severely aged specimens display no measurable glass transition up to the pyrolysis temperature of the matrix (above $400^{\circ} \mathrm{C}$ ). Therefore, the parameter $T_{g f}$ was determined by fitting equations (1) and (6) to data for unaged ( $a=0$ assumed) and severely aged ( $a=1$ assumed) specimens. This resulted in $T_{f f}=620^{\circ} \mathrm{C}$, which is not physically meaningful, being well above the pyrolysis temperature of the matrix, but it does provide a reasonable fit to available data, as illustrated in figures 4 and 5 .

\subsection{Mass Loss and Shrinkage Correlation}

Bowles et al. (ref. 7) provided complete information on the mass loss and shrinkage of neat resin specimens undergoing isothermal oxidative degradation at a number of different temperatures. They noted growth of a degradation layer near the surface and plotted thickness of this layer as a function of exposure time (ref. 7). These data are sufficiently detailed to validate the shrinkage model developed here.

In this report, the mass-loss data and the measured thicknesses of degraded layers are used to define the degradation state of the specimen in terms of the metrics defined in section 5. From the relations in sections 5 and 6 , the response of the degraded layer is found. Next, the relations in section 7 are used to predict the shrinkage of the entire specimen. The predicted and measured specimen shrinkages are then com-

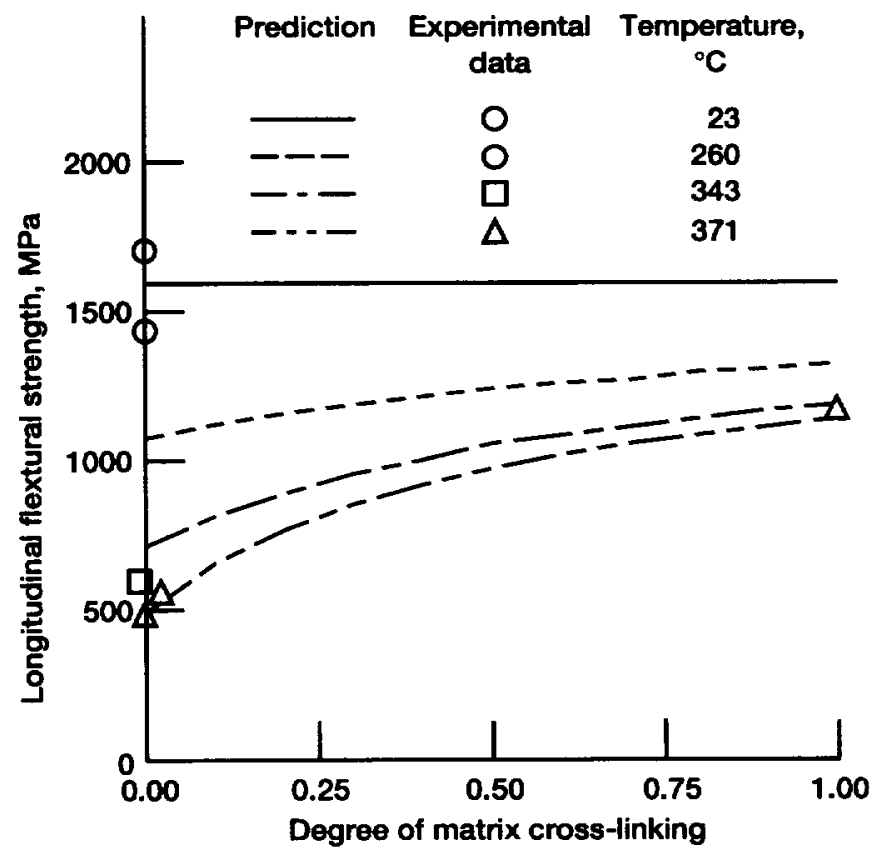

Figure 4.-Longitudinal bending strength correlation. Data of Bowles (ref. 9) and Vannucci and Cifani (ref. 2).

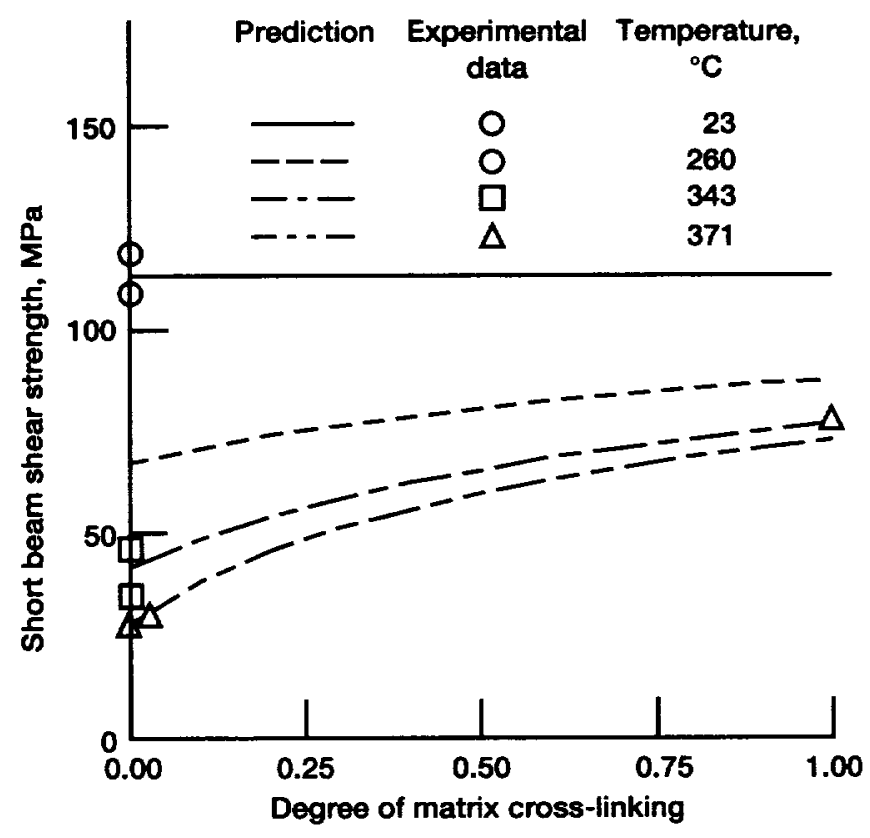

Figure 5.-Short beam shear strength correlation. Data of Bowles (ref. 9) and Vannucci and Cifani (ref. 2).

pared. As an additional check on the method, the calculations (which are tractable due to the simple geometry of the problem) were also carried out directly and checked against the code results.

The specimens were $6.4 \mathrm{~mm}$ square and $75 \mathrm{~mm}$ long. For the purpose of this correlation, they are modeled as threelayer laminates - two degraded layers and a nondegraded central core (see figs. 6 and 7). Such a model is accurate for axial stress and shrinkage predictions, which depend solely on the relative areas of the degraded and undegraded material. Here, all mass loss was assumed to take place in the degraded

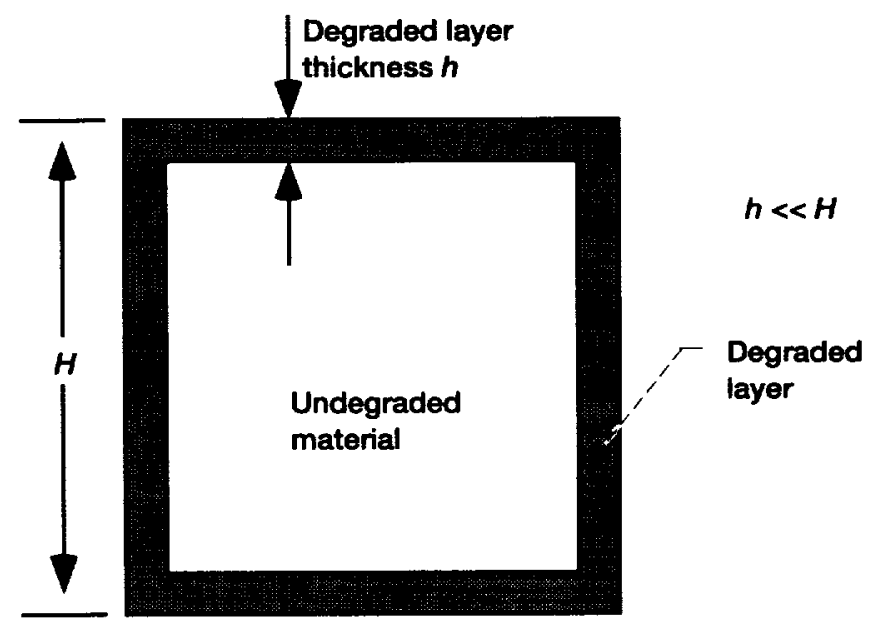

Figure 6.-Cross section of aged square cross-section specimen showing degraded layer. 


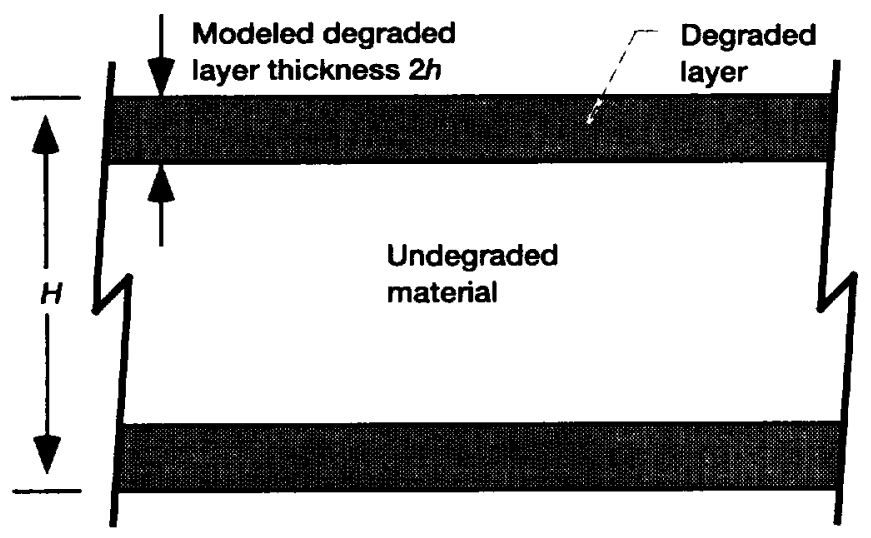

Figure 7.-Model of specimen as plate with same proportion of degraded material.

layers, and within these layers the mass loss was assumed uniform. Therefore, in the core $b=0$, and in the degraded layers

$$
b=\frac{\Delta m}{m_{d}}
$$

where $\Delta m$ is the measured mass change of the specimen and $m_{d}$ is the original mass of the material in the degraded layer as calculated from the geometry of the specimen, the density of the undegraded material, and the measured thickness of the degraded layer.

The measured degradation thickness and the calculated degradation parameter were used in the model shown in figure 7 to predict the longitudinal shrinkage of the specimen. Because of the changing thickness of the degraded layer, a new model was constructed for each temperature and exposure time. The shrinkage of the specimen was predicated on the assumptions that there were no mechanical loads or residual thermal stresses and that $a=1$ (based on the long exposure times), $D=0.1$ (based on the observation of moderate void formation in the degraded layer), and the room temperature material properties were unchanged by mass losses. Parametric studies showed that the results were relatively insensitive to these assumptions. Predicted and measured results are compared in figure 8 . As can be seen, the correlation is quite good.

The predicted results also provide insight into the response of these specimens during exposure. The mass loss in the surface layer results in shrinkage, which is constrained by the unshrinking, undegraded core material. The results are a net shrinkage of the entire specimen, and stresses occurring in both the degraded layers and the core. The stresses in the core are compressive, and the stresses in the degraded layer are tensile. These stresses reach a magnitude that is sufficient to cause failure in the degraded layer. Although insufficient data

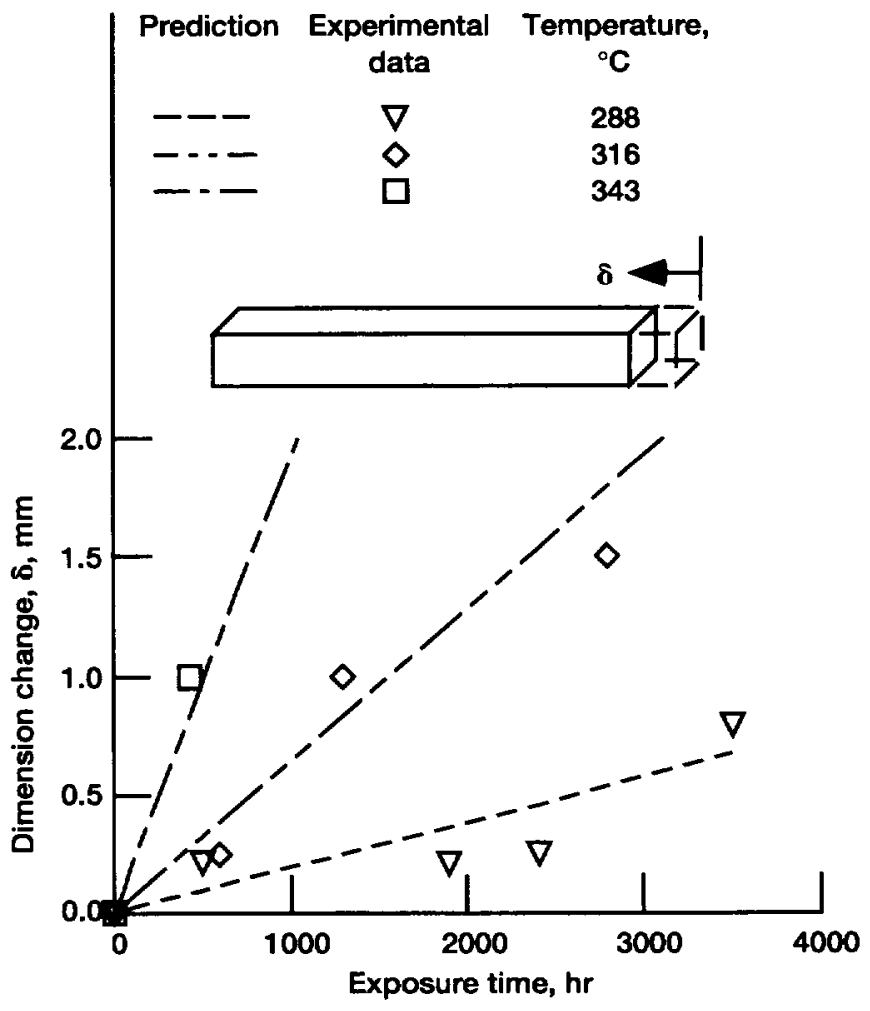

Figure 8.-Comparison of predicted and measured changes in longitudinal dimension (predictions are based on degraded layer thickness and mass-loss data).

were provided in reference 7 for a quantitative correlation of this effect, the predicted failure in the surface layers qualitatively agrees with the observed cracking of the surface layer.

\subsection{Surface Cracking Study}

The consequences of mass loss near the surface of composite specimens was parametrically studied. Figure 9 shows a $[0 / \pm 45 / 90] s$ laminate with mass-loss degradation occurring only in the surface plies. The specimen was assumed to have been exposed to high-temperature conditions long enough to fully cross-link the matrix $(a=1)$. The stresses in the surface plies of an unloaded laminate were examined as mass-loss parameter $b$ was increased.

Figure 10 shows the fiber-direction and transverse stresses in the outer plies of the laminate shown in figure 9 as functions of mass loss in these plies. A constant temperature of $371^{\circ} \mathrm{C}$ is assumed. Large stresses occur in these plies because of the matrix shrinkage associated with mass loss. A transverse ply tensile strength of about $30 \mathrm{MPa}$ is predicted at this temperature, implying the stresses are sufficient to cause ply cracking at about 5-percent mass loss in the surface plies. The maximum matrix stresses at the micromechanical level, 


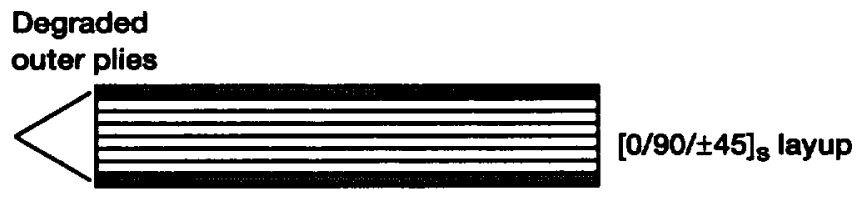

Figure 9.-Laminate with degraded surface plies.

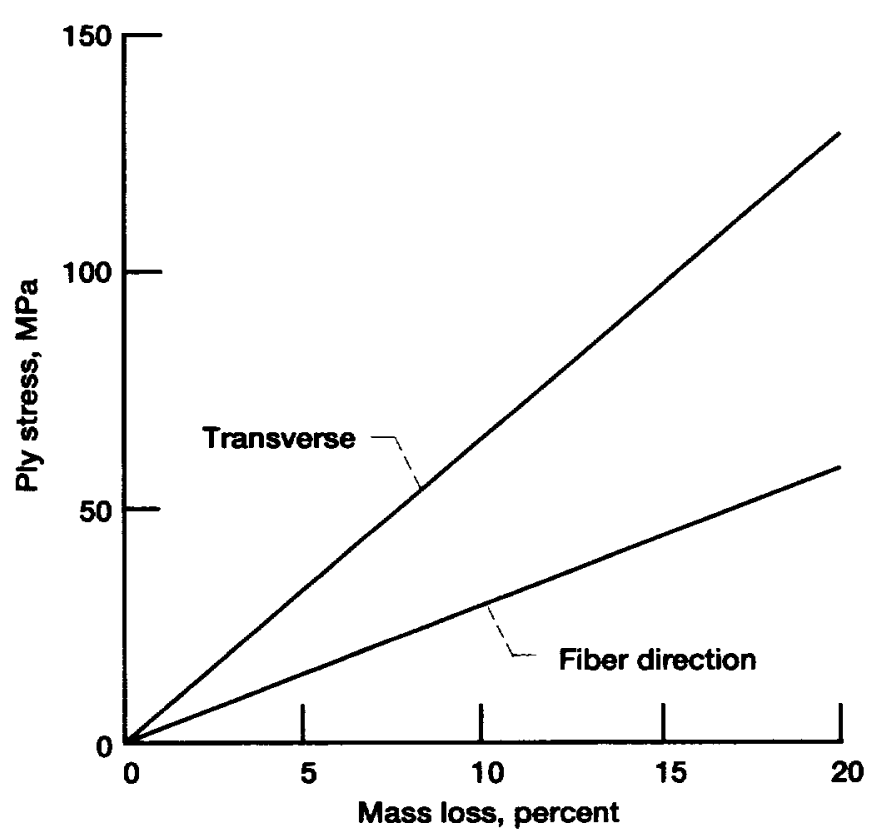

Figure 10.-Ply stresses in surface plies at $371^{\circ} \mathrm{C}$.

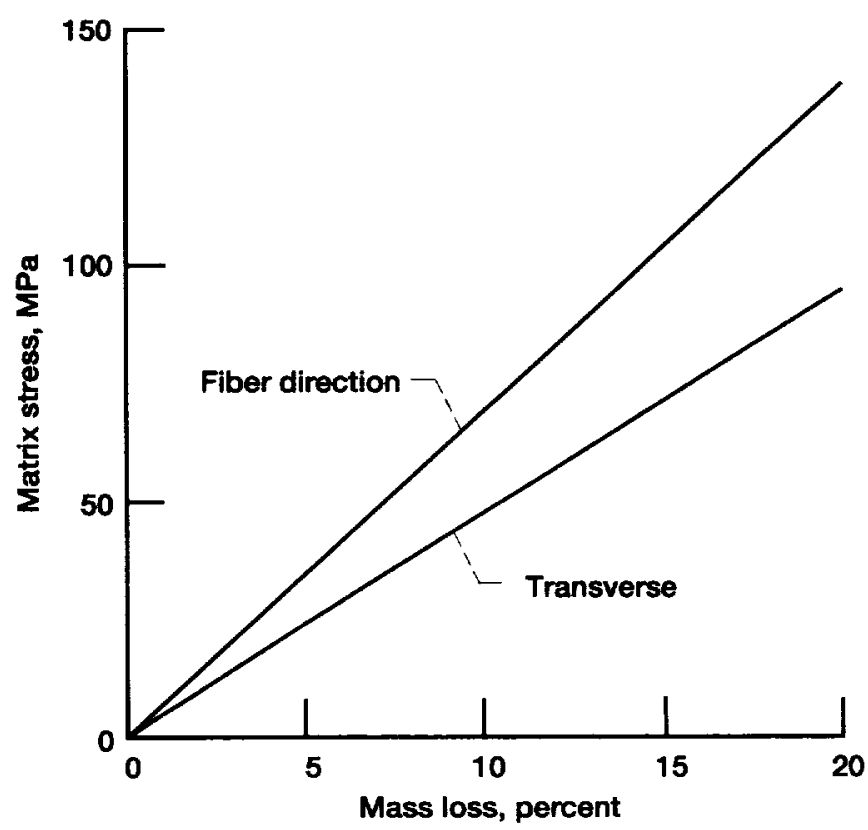

Figure 11.-Shrinkage-induced microstresses in matrix of surface plies at $371^{\circ} \mathrm{C}$.

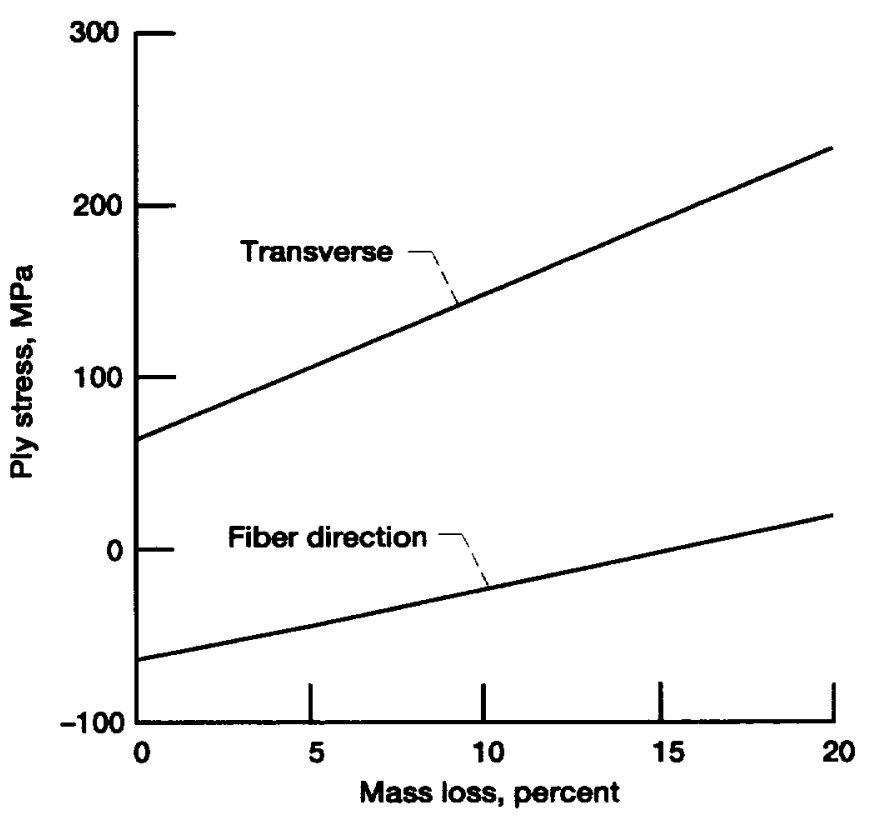

Figure 12.-Ply stresses in surface plies at $25^{\circ} \mathrm{C}$.

calculated from equations (28) and (30), are shown in figure 11. They are somewhat higher than the ply stresses. The ply stresses at room temperature are shown in figure 12; they are much higher than the stresses at high temperature because of the presence of residual curing stresses (the cure temperature was assumed to be $371^{\circ} \mathrm{C}$ ) and the fact that the matrix is stiffer at room temperature. Although the matrix is also much stronger at room temperature, the stresses are easily sufficient to cause cracking in this case. Even at zero mass loss, the stresses are very close to the transverse strength of the matrix. This raises the possibility that specimens with small mass losses may not crack at the aging temperature, but may crack when returned to room temperature.

Figures 13 to 15 show how varying other parameters effects the outer ply stresses. A baseline case of $371^{\circ} \mathrm{C}$ and 5 -percent mass loss in the outer plies was used. Figure 13 shows that if some mass loss is occurring in the bulk of the material (the default case assumed all of the mass loss was in the surface plies) the fiber-direction stresses are lowered, but not the critical transverse stresses. Figure 14 shows that if some of the mass loss is due to void formation instead of shrinkage, stresses are reduced proportionally. On the other hand, different assumptions about the reduction of room temperature material properties with degradation have little effect on the calculated stresses. Figure 15 shows the effect of different material degradation parameters $\Delta E_{a}, \Delta S_{a}$, and $\Delta \alpha_{a}$ (transverse properties), which varied between 0 and -1.0 , and their respective degradation exponents $n_{E a}, n_{S a}$, and $n_{\alpha a}$, which varied from 0.5 to 1.0 . 


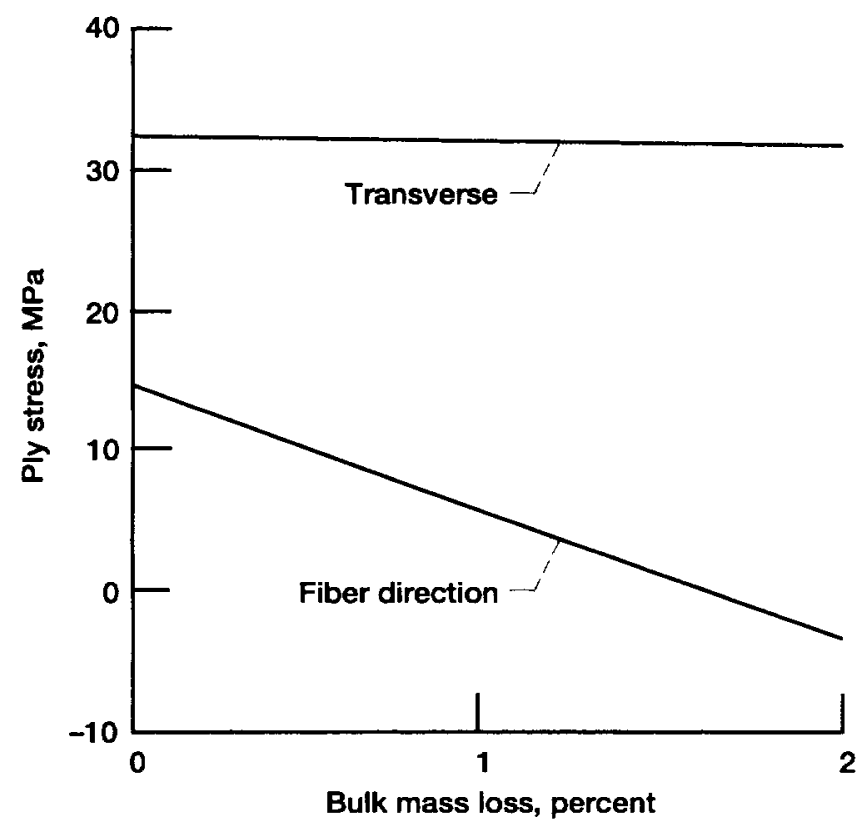

Figure 13.-Effect of bulk mass loss on surface ply stresses (temperature, $371^{\circ} \mathrm{C}$; surface ply mass loss, 5 percent).

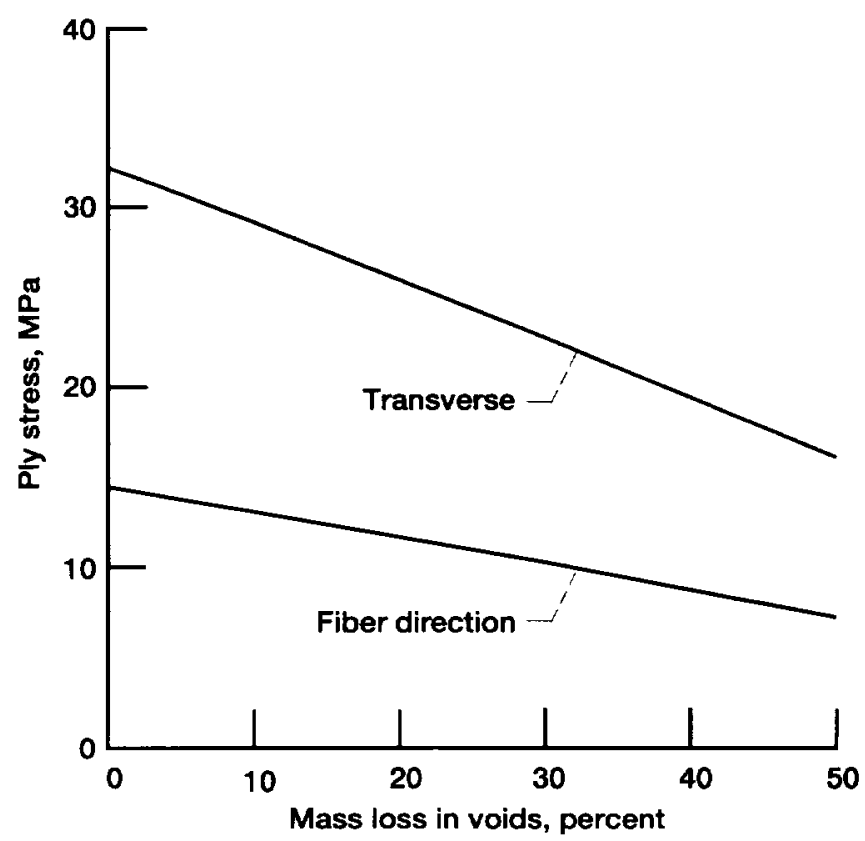

Figure 14.-Effect of void formation on surface ply stresses (temperature, $371^{\circ} \mathrm{C}$; surface ply mass loss, 5 percent).

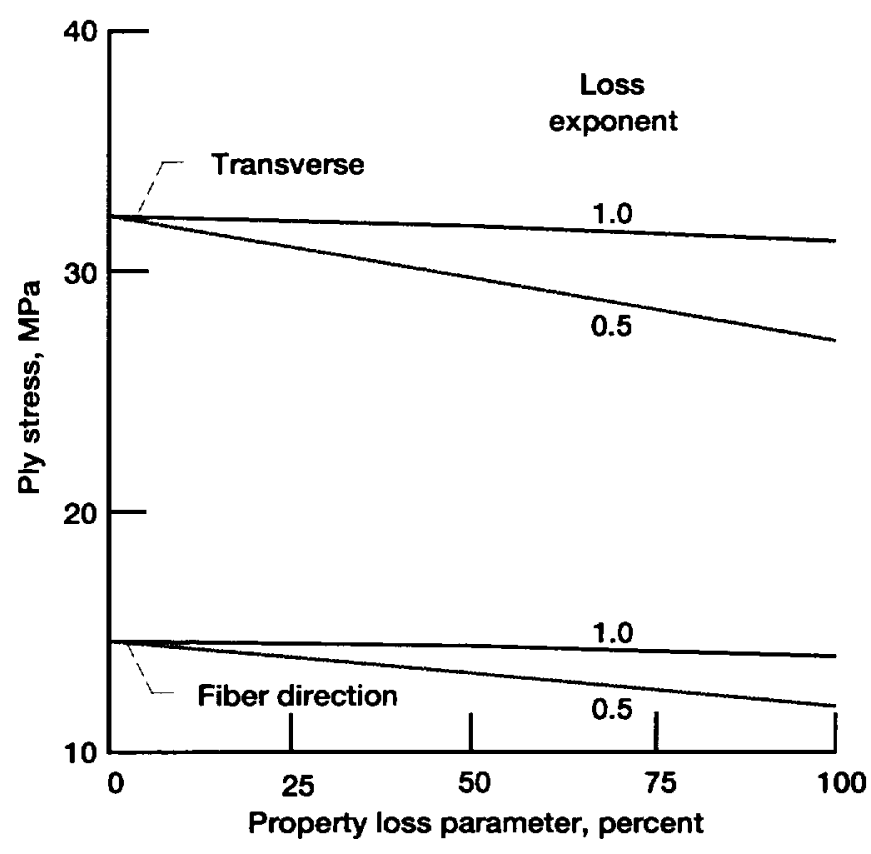

Figure 15.-Effect of material property changes on surface ply stresses (temperature, $371^{\circ} \mathrm{C}$; surface ply mass loss, 5 percent).

\subsection{Longitudinal Bending Test Simulation}

A 16-ply unidirectional specimen $2.24 \mathrm{~mm}$ thick, aged at $371{ }^{\circ} \mathrm{C}$, was examined. Aging and degradation of the specimen were assumed to be functions of time. The cross-linking metric $a$ in all plies and the degradation metric $b$ in the surface plies ( $b=0$ elsewhere) are shown in figure 16. These curves are approximations based on experimentally observed behavior. The assumption of rapid completion of cross-linking was based on information provided in reference 9 . The mass loss was computed from equation (78) by using the assumed curve for $b$; the results compare well with the data of reference 2 . Note that the massive mass loss in the surface plies correlates with the observation that bare fibers eventually flaked off the specimens.

The bending strength of the modeled specimens was computed by applying a trial bending load and comparing the stress in the outer ply on the compressive side of the specimen to the ultimate bending strength for this ply as computed by the code. The calculated results were iterated until the bending load necessary to just fail the specimen was found. The results are presented in figure 17. Two types of "failure stress" are shown: the stress in the center of the outer ply at failure as calculated by the code, and the equivalent stress calculated for a uniform piece of material being tested. The data from reference 2 were assumed to have been reduced in this way. This equivalent stress is 


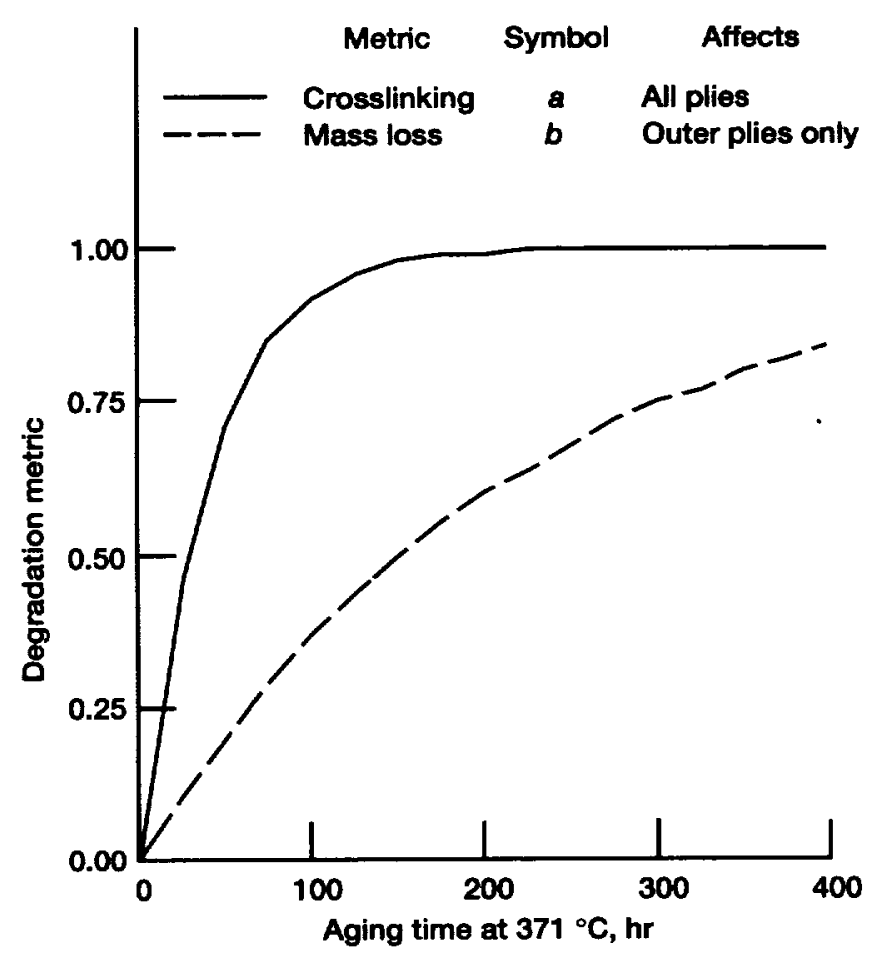

Figure 16.-Assumed degradations as function of aging time.

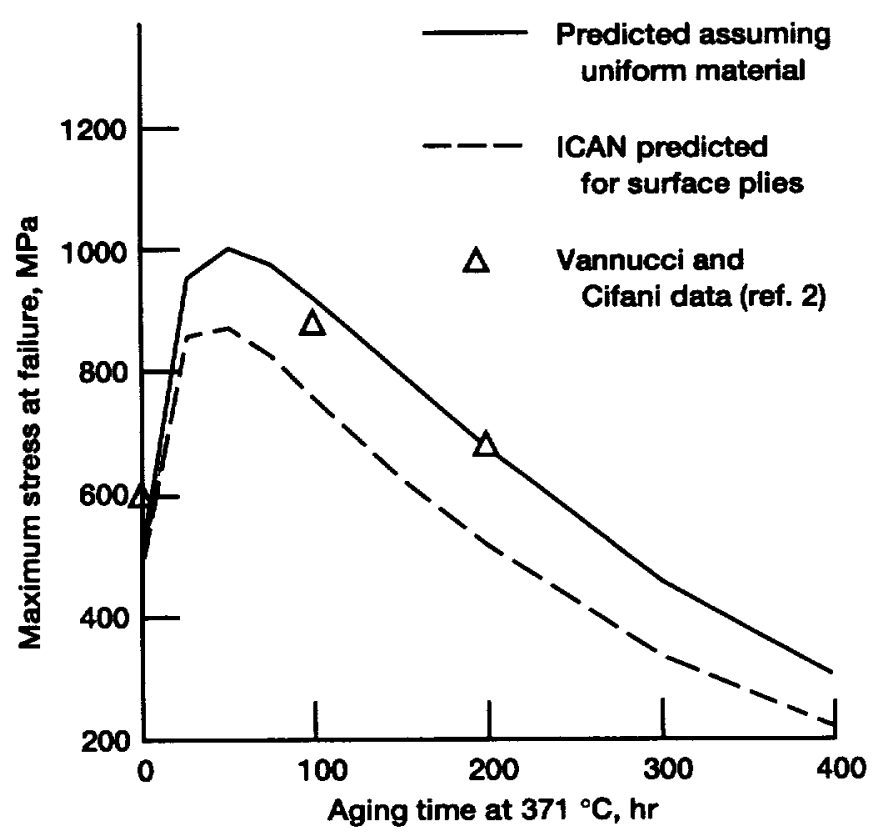

Figure 17.-Longitudinal bending test correlation.

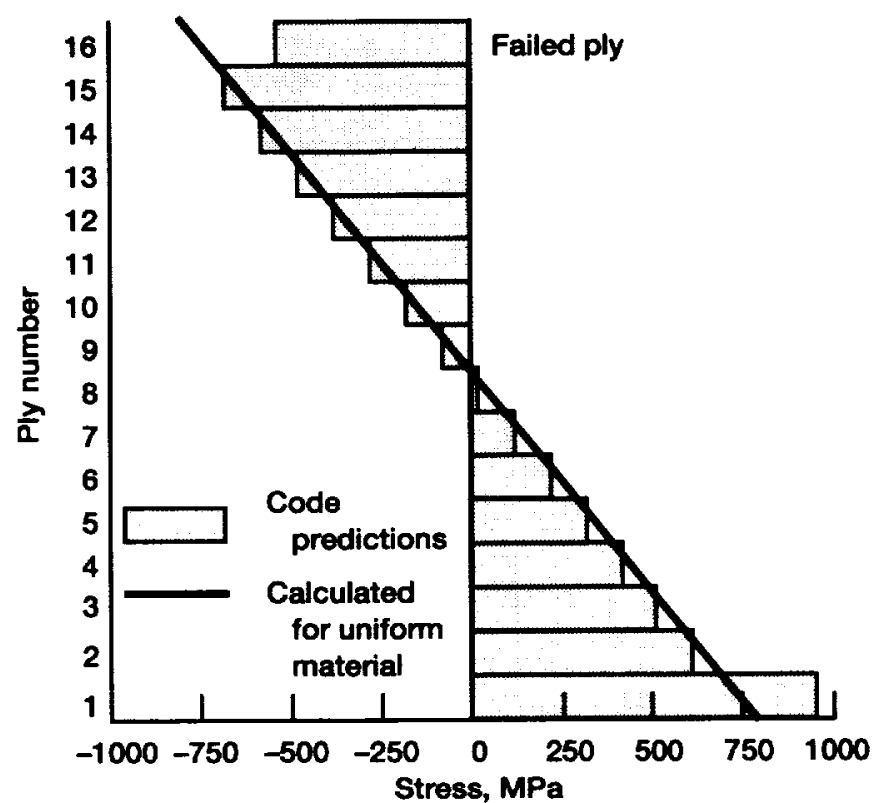

Figure 18.-Comparison of ply stresses predicted by code to stresses calculated by assuming uniform material at time of failure for specimens aged $150 \mathrm{hr}$.

$$
\sigma^{e q}=\frac{6 M}{H^{2}}
$$

where $M$ is the applied bending load at failure, and $H$ is the laminate thickness. The results are seen to be very good in terms of matching measured and calculated equivalent stresses, but the equivalent stress and the actual failure stress are not the same because of the nonuniformity of the material. This problem is illustrated in figure 18 , which shows the stresses at the point of failure in each ply in a sample aged for $150 \mathrm{hr}$. The apparent stepwise variation in the stresses is an artifact of the code's calculation of a single stress for each ply and is not important. However, the top and bottom plies have stresses that differ significantly from those predicted for a uniform material. This effect complicates accurate interpretation of bending test data.

\subsection{Transverse Bending Test Simulation}

The data of transverse bending tests have been found to be very sensitive to aging (ref. 16), which suggests that these tests may be useful for screening materials. A transverse bending test simulation was attempted with the code, but the test failed, for interesting reasons. It was found that under the same aging conditions assumed in the longitudinal bending simulation described in section 9.4, the surface plies cracked and lost transverse load-carrying capability, even without a 
load being applied. If the remaining strength of the specimens were calculated by assuming the surface plies did not exist, the results were not conservative. Evidently the surface plies provide starter cracks that badly weaken the specimens. Such cracks have been noted, as has their tendency to become selfperpetuating since they provide a pathway for air and promote additional oxidation. This phenomenon is beyond current analytical capabilities, and it greatly complicates the quantitative interpretation of the results of transverse bending tests.

\subsection{Conclusions}

A model of the effects of material degradation on the stress state in polymer matrix composites has been developed and demonstrated. It successfully replicates the behavior observed in laminates undergoing isothermal aging. The increase in high-temperature properties in the early phases of hightemperature exposure was assumed to be due to matrix crosslinking and was modeled semi-empirically. Further exposure effects were primarily mass loss and resultant shrinkage near the surface. Micromechanical and laminate theory relations for predicting ply and laminate behavior due to shrinkage and property changes were developed and verified. It was found that nonuniform shrinkage causes stresses, which can in turn cause ply cracking. Degradation also creates a nonuniform material, which makes the interpretation of existing test data difficult. The stress at failure in a longitudinal bending test is not the same as that calculated by assuming a uniform material, for example. The cracks also strongly affect the results of transverse bending tests, thereby making the results of these tests very difficult to use quantitatively.

\section{Acknowledgments}

This work was supported by an American Society of Electrical Engineers fellowship and performed under the direction of Dr. Chris C. Chamis at the NASA Lewis Research Center. The preparation of this manuscript was also partially supported by a National Science Foundation Young Investigator Award. The authors thank Gary Roberts and Kenneth Bowles of NASA Lewis, and Dr. Surendra Singhal of NYMA, Inc., for their assistance and support.

\section{Lewis Research Center}

National Aeronautics and Space Administration

Cleveland, Ohio, July 5, 1995 


\subsection{Appendix A}

Symbols

\begin{tabular}{|c|c|c|c|}
\hline $\mathbf{A}$ & laminate in-plane stiffness matrix & $\mathbf{Q}$ & reduced stiffness matrix \\
\hline $\mathbf{a}$ & inverse laminate in-plane stiffness matrix & $\overline{\mathbf{Q}}$ & rotated reduced stiffness matrix \\
\hline$a$ & cross-linking metric & $R_{l}$ & failure stress ratio \\
\hline B & laminate coupling stiffness matrix & $S$ & composite strength \\
\hline b & inverse laminate coupling stiffness matrix & $\Delta S$ & normalized change in matrix strength properties \\
\hline$b$ & mass-loss metric & $\mathbf{T}$ & transform matrix \\
\hline C & shrinkage constant for cross-linking mechanism & $T$ & temperature \\
\hline D & laminate bending stiffness matrix & $T_{s f}$ & stress-free temperature of laminate \\
\hline$D$ & fraction of mass loss due to changes in porosity & $\Delta T$ & change in temperature \\
\hline d & inverse laminate bending stiffness matrix & $V$ & volume of material in control volume \\
\hline$E$ & Young's modulus & $z$ & distance from centerline of ply to laminate centerline \\
\hline$\Delta E$ & normalized change in matrix stiffness properties & $z^{b}$ & distance from bottom of ply to laminate centerline \\
\hline$G$ & shear modulus & $z^{t}$ & distance from top of ply to laminate centerline \\
\hline$H$ & laminate thickness & $\alpha$ & thermal expansion coefficient \\
\hline$k$ & degraded layer thickness & $\Delta \alpha$ & $\begin{array}{l}\text { normalized change in matrix coefficient of thermal } \\
\text { expansion }\end{array}$ \\
\hline$l$ & side length of control volume & $\beta$ & moisture expansion coefficient \\
\hline $\mathbf{M}$ & applied moment vector & $\delta$ & specimen length change \\
\hline$M$ & applied bending load at failure & $\mathbf{E}$ & strain vector \\
\hline$\Delta M$ & percent moisture content by weight & $\boldsymbol{\varepsilon}$ & rotated strain vector \\
\hline$m$ & mass in control volume & $\varepsilon_{\mathbf{o}}$ & laminate strain vector \\
\hline$\Delta m$ & measured mass change & $\varepsilon$ & matrix strain \\
\hline $\mathbf{N}$ & applied force vector & $\zeta$ & shrinkage coefficient for cross-linking mechanism \\
\hline$N$ & number of plies in laminate & $\boldsymbol{\theta}$ & ply angle \\
\hline$P(T)$ & matrix property at temperature $T$ & $\boldsymbol{\kappa}$ & laminate curvature vector \\
\hline
\end{tabular}




\begin{tabular}{|c|c|c|c|}
\hline$v$ & Poisson's ratio & $B$ & region $B$ in composite microstructure model \\
\hline$\rho$ & density & $b$ & $\begin{array}{l}\text { associated with second degradation (mass-loss) } \\
\text { mechanism }\end{array}$ \\
\hline \multirow[t]{2}{*}{$\overline{\boldsymbol{\sigma}}$} & rotated stress vector & & \\
\hline & & $C$ & compressive \\
\hline \multirow[t]{2}{*}{$\sigma$} & stress in component & & \\
\hline & & $d$ & initially degraded \\
\hline \multirow[t]{2}{*}{$\sigma^{e q}$} & maximum stress in uniform beam at failure & & \\
\hline & & $f$ & in fiber direction \\
\hline \multirow[t]{2}{*}{$\phi$} & porosity & & \\
\hline & & $g$ & glass transition \\
\hline \multirow[t]{2}{*}{$\chi$} & shrinkage coefficient for mass-loss mechanism & & \\
\hline & & $g f$ & final glass transition \\
\hline \multicolumn{4}{|c|}{ Superscripts: } \\
\hline & & $i$ & relating to ply $I$ \\
\hline \multirow[t]{2}{*}{$b$} & bottom & & \\
\hline & & $i j$ & in $i j$ direction \\
\hline \multirow[t]{2}{*}{$H$} & hygral & & \\
\hline & & $\ell$ & composite \\
\hline \multirow[t]{2}{*}{$n$} & shrinkage exponent for cross-linking mechanism & & \\
\hline & & $\ell 11$ & composite fiber direction \\
\hline \multirow[t]{3}{*}{$n_{E a}, n_{E b}$} & exponents of change in matrix stiffness properties & & \\
\hline & $\begin{array}{l}\text { associated with first and second degradation } \\
\text { mechanisms }\end{array}$ & $\ell 12$ & composite shear direction \\
\hline & & $\ell 22$ & composite transverse direction \\
\hline \multirow{3}{*}{$n_{S a}, n_{S b}$} & exponents of change in matrix strength properties & & \\
\hline & $\begin{array}{l}\text { associated with first and second degradation } \\
\text { mechanisms }\end{array}$ & $m$ & matrix \\
\hline & & $o$ & initial value \\
\hline \multirow[t]{2}{*}{$n_{a a}, n_{a b}$} & $\begin{array}{l}\text { exponents of change in matrix coefficients of ther- } \\
\text { mal expansion associated with first and second } \\
\text { degradation mechanisms }\end{array}$ & $R T$ & room temperature \\
\hline & & $S$ & shear \\
\hline \multirow[t]{2}{*}{$T$} & thermal & & \\
\hline & & $s$ & shear \\
\hline \multirow[t]{2}{*}{$\mathbf{T}$} & matrix transpose & & \\
\hline & & $T$ & tensile \\
\hline \multirow[t]{2}{*}{$t$} & top & & \\
\hline & & $t$ & in transverse direction \\
\hline \multirow[t]{2}{*}{$*$} & shrinkage & & \\
\hline & & $v$ & void \\
\hline \multicolumn{4}{|c|}{ Subscripts: } \\
\hline & & $x$ & component $x$ \\
\hline$A$ & region $A$ in composite microstructure model & & \\
\hline$a$ & $\begin{array}{l}\text { associated with first degradation (cross-link) } \\
\text { mechanism }\end{array}$ & & \\
\hline
\end{tabular}




\subsection{Appendix B}

\section{Summary of Classical Laminate Theory of Equations}

For each ply $i$, we have ply properties $E_{\ell 11 i}$ (fiber-direction stiffness), $E_{\ell 22 i}$ (transverse stiffness), $v_{\ell 12 i}$ (major Poisson's ratio), $G_{\ell 12 i}$ (shear stiffness), $\alpha_{\ell 11 i}$ and $\beta_{\ell 11 i}$ (fiber direction coefficient of thermal expansion (CTE) and moisture swelling coefficient), and $\alpha_{\ell 22 i}$ and $\beta_{\ell 22 i}$ (transverse CTE and coefficient of mechanical expansion (CME)). The fibers are aligned at an angle $\theta_{\mathrm{i}}$ to the structural $x$-axis. For each ply $i$,

where

$$
\mathbf{Q}_{i}=\left[\begin{array}{ccc}
Q_{11(i)} & Q_{12(i)} & 0 \\
Q_{12(i)} & Q_{22(i)} & 0 \\
0 & 0 & Q_{66(i)}
\end{array}\right]
$$

$$
\begin{gathered}
Q_{11(i)}=E_{\ell 11 i} / D_{i} \\
Q_{12(i)}=v_{\ell 12 i} E_{\ell 22 i} / D_{i} \\
Q_{22(i)}=E_{\ell 22 i} / D_{i} \\
Q_{66(i)}=G_{\ell 12 i} / D_{i} \\
D_{(i)}=1+v_{\ell 12 i}^{2} E_{\ell 22 i} / E_{\ell 11 i}
\end{gathered}
$$

and

$$
\overline{\mathbf{Q}}_{i}=\mathbf{T}_{i}^{-1} \mathbf{Q}_{i} \mathbf{T}_{i}^{-\mathbf{T}}
$$

for

$$
\mathbf{T}_{i}=\left[\begin{array}{ccc}
\cos ^{2} \theta_{i} & \sin ^{2} \theta_{i} & 2 \sin \theta_{i} \cos \theta_{i} \\
\sin ^{2} \theta_{i} & \cos ^{2} \theta_{i} & -2 \sin \theta_{i} \cos \theta_{i} \\
-\sin \theta_{i} \cos \theta_{i} & \sin \theta_{i} \cos \theta_{i} & \cos ^{2} \theta_{i}-\sin ^{2} \theta_{i}
\end{array}\right]
$$

For a laminate with $N$ plies,

$$
\mathbf{A}=\sum_{i=1}^{N} \overline{\mathbf{Q}}_{i}\left(z_{i}^{t}-z_{i}^{b}\right)
$$

$$
\mathbf{B}=\frac{1}{2} \sum_{i=1}^{N} \overline{\mathbf{Q}}_{i}\left[\left(z_{i}^{t}\right)^{2}-\left(z_{i}^{b}\right)^{2}\right]
$$

and

$$
\mathbf{D}=\frac{1}{3} \sum_{i=1}^{N} \overline{\mathbf{Q}}_{i}\left[\left(z_{i}^{t}\right)^{3}-\left(z_{i}^{b}\right)^{3}\right]
$$

where $z_{i}^{t}$ and $z_{i}^{b}$ represent the distances from the top and the bottom of the ply to the laminate centerline, respectively. Assembling these $3 \times 3$ matrixes into a $6 \times 6$ matrix and inverting yields

$$
\left[\begin{array}{ll}
\mathbf{a} & \mathbf{b} \\
\mathbf{b}^{\top} & \mathbf{d}
\end{array}\right]=\left[\begin{array}{ll}
\mathbf{A} & \mathbf{B} \\
\mathbf{B} & \mathbf{D}
\end{array}\right]^{-1}
$$

where $\mathbf{a}, \mathbf{b}$, and $\mathbf{d}$ are the compliance submatrices for the laminate.

For $\Delta T_{i}=T_{i}-T_{s f}$ where $T_{s f}$ is the stress-free temperature of the laminate, $T_{i}$ is its temperature, and $\Delta M$ is its percent moisture content by weight, the ply thermal strains are given by

$$
\varepsilon_{\ell(i)}^{T}=\left\{\begin{array}{c}
\alpha_{l} \\
\alpha_{t} \\
o
\end{array}\right\}_{i}^{\Delta T_{i}}
$$

The ply moisture strains are given by

$$
\varepsilon_{\ell(i)}^{H}=\left\{\begin{array}{l}
\beta_{l} \\
\beta_{t} \\
0
\end{array}\right\}_{i} \Delta M_{i}
$$

and the corresponding rotated ply strains about the structural $\mathrm{x}$-axis are given by 


$$
\left.\begin{array}{l}
\bar{\varepsilon}_{\ell(i)}^{T}=\mathbf{T}^{-\mathbf{T}} \varepsilon_{\ell(i)}^{T} \\
\bar{\varepsilon}_{\ell(i)}^{H}=\mathbf{T}^{-\mathrm{T}} \varepsilon_{\ell(i)}^{H}
\end{array}\right\}
$$

and the laminate moments are given by

where $\mathbf{T}$ is defined in equation (B2).

The respective laminate in-place forces are given by

$$
\left.\begin{array}{l}
\mathbf{N}^{T}=\sum_{i=1}^{N} \overline{\mathbf{Q}}_{i} \bar{\varepsilon}_{\ell(i)}^{T}\left(z_{i}^{t}-z_{i}^{b}\right) \\
\mathbf{N}^{H}=\sum_{i=1}^{N} \overline{\mathbf{Q}}_{i} \bar{\varepsilon}_{\ell(i)}^{H}\left(z_{i}^{t}-z_{i}^{b}\right)
\end{array}\right\}
$$$$
\mathbf{M}^{T}=\frac{1}{2} \sum_{i=1}^{N} \overline{\mathbf{Q}}_{i} \bar{\varepsilon}_{\ell(i)}^{T}\left[\left(z_{i}^{t}\right)^{2}-\left(z_{i}^{b}\right)^{2}\right]
$$$$
\mathbf{M}^{H}=\frac{1}{2} \sum_{i=1}^{N} \overline{\mathbf{Q}}_{i} \bar{\varepsilon}_{\ell(i)}^{H}\left[\left(z_{i}^{t}\right)^{2}-\left(z_{i}^{b}\right)^{2}\right]
$$ 


\subsection{Appendix C}

\section{Modified Input File}

A complete description of the input to the ICAN code is contained in reference 11 . Here we will illustrate the new input features by an example input file, with new input fields in bold. This file must reside in the same folder as ICAN. It can have any name; ICAN will ask for an input file name when it is launched.

\begin{tabular}{|c|c|c|c|c|c|c|c|c|c|}
\hline \multicolumn{10}{|c|}{ Parametric Study input file, C-6000/PMR-15 composite } \\
\hline COMSAT & $\mathbf{T}$ & & & & & & & & \\
\hline CSANB & $\mathbf{F}$ & & & & & & & & \\
\hline BIDE & $\mathbf{F}$ & & & & & & & & \\
\hline RINDV & $\mathbf{F}$ & & & & & & & & \\
\hline NONUDF & $\mathbf{T}$ & & & & & & & & \\
\hline DEFECT & $\mathbf{F}$ & & & & & & & & \\
\hline PLY & 1 & 2 & 700.00 & 700.00 & 0.00 & 0.000 . & .005500 & 1.00 & 0.10 \\
\hline PLY & 2 & 1 & 700.00 & 700.00 & 0.00 & 45.000 . & .005500 & 1.00 & 0.01 \\
\hline PLY & 3 & 1 & 700.00 & 700.00 & 0.00 & -45.000 & .005500 & 1.00 & 0.01 \\
\hline PLY & 4 & 1 & 700.00 & 700.00 & 0.00 & 90.000 . & .005500 & 1.00 & 0.01 \\
\hline PLY & 5 & 1 & 700.00 & 700.00 & 0.00 & 90.000 & .005500 & 1.00 & 0.01 \\
\hline PLY & 6 & 1 & 700.00 & 700.00 & 0.00 & -45.000 & .005500 & 1.00 & 0.01 \\
\hline PLY & 7 & 1 & 700.00 & 700.00 & 0.00 & 45.000 & .005500 & 1.00 & 0.01 \\
\hline PLY & 8 & 2 & 700.00 & 700.00 & 0.00 & 0.000 & .005500 & 1.00 & 0.10 \\
\hline MATCRD & & $\mathrm{IHM}$ & 10.5800 & $0.0001 \mathrm{C}$ & MHM & 0.0000 & 0.0000 & 0.0000 & \\
\hline MATCRD & & $\mathbf{I H M}$ & 10.5800 & $0.0001 \mathrm{C}$ & MHM & 0.0000 & 0.0000 & 0.0000 & \\
\hline PLOAD & & & & & & & & & \\
\hline PLOAD & & & & & & & & & \\
\hline PLOAD & & & & & & & & & \\
\hline OPTION & 5 & & & & & & & & \\
\hline OPTION & 7 & & & & & & & & \\
\hline OPTION & 11 & & & & & & & & \\
\hline OPTION & 12 & & & & & & & & \\
\hline OPTION & 15 & & & & & & & & \\
\hline
\end{tabular}

The two additional eight-character fields on the PLY cards are the input values of the degradation metrics $a$ and $b$ for each ply. In this example, all plies are fully cross-linked, the surface plies have suffered 10-percent matrix mass loss, and the inner plies have suffered 1-percent matrix mass loss. The existing ICAN convention, which requires a unique MATCRD card for plies with different temperatures, applies to the degradation state. For each unique degradation state, a separate MATCRD card must be used. In this example, two states exist, distinguished by two different values of $b$, so two MATCRD cards are used.

No choice of output OPTION is required. If any nonzero degradation is specified, the degradation-induced property and stress output will be provided automatically. 


\subsection{Appendix D}

\section{Degraded File}

A complete description of the material files used by the ICAN code is contained in reference 11. Here we list the new material properties used for this study and illustrate the new degradation constant inputs. Material properties are stored in a file named MAT.DAT, which must reside in the same folder as the ICAN code. Degradation constants for matrix materials are preceded by a single line containing only the characters DEGRADATION CONSTANTS. This line must immediately follow the regular material properties. If degradation constants are not provided, but nonzero degradation is specified for any plies, then default values are used.

\section{FIBER PROPERTIES}

$\begin{array}{llll}\text { C-6K C-6000 EQUIVALENT FIBER PROPERTIES (H. MCMANUS 8-93) } \\ \$ & & & \\ \$ & & & \\ \$ & & & \\ \text { Number of fibers per end } & \text { Nf } & 15000 & \text { number } \\ \text { Filament equivalent diameter } & \text { df } & 0.280 \mathrm{E}-03 & \text { inches } \\ \text { Weight density } & \text { Rhof } & 0.640 \mathrm{E}-01 & \text { lb/in**3 } \\ \text { Normal moduli (11) } & \text { Ef11 } & 0.340 \mathrm{E}+08 & \mathrm{psi} \\ \text { Normal moduli (22) } & \text { Ef22 } & 0.220 \mathrm{E}+07 & \mathrm{psi} \\ \text { Poisson's ratio (12) } & \text { Nuf12 } & 0.220 \mathrm{E}+00 & \text { non-dim } \\ \text { Poisson's ratio (23) } & \text { Nuf23 } & 0.250 \mathrm{E}+00 & \text { non-dim } \\ \text { Shear moduli (12) } & \text { Gf12 } & 0.540 \mathrm{E}+07 & \mathrm{psi} \\ \text { Shear moduli (23) } & \text { Gf23 } & 0.110 \mathrm{E}+07 & \mathrm{psi} \\ \text { Thermal expansion coef. (11) } & \text { Alfaf11 } & -.590 \mathrm{E}-06 & \text { in/in/F } \\ \text { Thermal expansion coef. (22) } & \text { Alfaf22 } & 0.560 \mathrm{E}-05 & \text { in/in/F } \\ \text { Heat conductivity (11) } & \text { Kf11 } & 0.440 \mathrm{E}+01 & \mathrm{BTU}-\mathrm{in} / \mathrm{hr} / \mathrm{in} * * 2 / \mathrm{F} \\ \text { Heat conductivity (22) } & \text { Kf22 } & 0.440 \mathrm{E}+00 & \mathrm{BTU}-\mathrm{in} / \mathrm{hr} / \mathrm{in} * * 2 / \mathrm{F} \\ \text { Heat capacity } & \text { Cf } & 0.166 \mathrm{E}+00 & \mathrm{BTU} / \mathrm{b} / \mathrm{F} \\ \text { Fiber tensile strength } & \text { SfT } & 0.550 \mathrm{E}+06 & \mathrm{psi} \\ \text { Fiber compressive strength } & \text { SfC } & 0.650 \mathrm{E}+06 & \mathrm{psi} \\ & & & \end{array}$

OVER END OF FIBER PROPERTIES

\section{MATRIX PROPERTIES}

PMHM PMR-15 POLYIMIDE MATRIX modified by H. McManus 8-93

$\$$ increased initial $\mathrm{Tg}$ to match Vannucci data

$\$$ increased shear strength

$\$$

Weight density

Normal modulus

Poisson's ratio

Thermal expansion coef.

Matrix heat conductivity

Heat capacity

Matrix tensile strength

Matrix compressive strength

Matrix shear strength

Allowable tensile strain

Allowable compr. strain

Allowable shear strain

Allowable torsional strain

Void heat conductivity

Glass transition temperature

DEGRADATION CONSTANTS

Max aged glass transition $T$

Shrinkage due to crosslinking

exponent for above

void frac delta from mass loss

Changes in properties (D)

(dimensionless fraction of

original properties)

and corresponding exponents

(n) for crosslink (1) and

massloss (2) aging

$\mathrm{E}=$ modulus

$\mathbf{S}=$ all strengths

alf $=$ CTE

\begin{tabular}{|c|c|c|}
\hline Rhom & $0.440 \mathrm{E}-01$ & $1 \mathrm{~b} / \mathrm{in}^{* * 3}$ \\
\hline Em & $0.470 \mathrm{E}+06$ & psi \\
\hline Num & $0.360 \mathrm{E}+\infty 0$ & non-dim \\
\hline Alfa m & $0.280 \mathrm{E}-04$ & in/in/F \\
\hline $\mathrm{Km}$ & $0.146 \mathrm{E}+00$ & BTU-in/hr/in**2/F \\
\hline $\mathrm{Cm}$ & $0.250 \mathrm{E}+00$ & BTU/b/F \\
\hline $\operatorname{SmT}$ & $0.810 E+04$ & psi \\
\hline $\mathrm{SmC}$ & $0.165 \mathrm{E}+05$ & psi \\
\hline $\mathrm{SmS}$ & $0.135 E+05$ & psi \\
\hline eps $\mathrm{mT}$ & $0.183 \mathrm{E}-01$ & in/in \\
\hline eps $\mathrm{mC}$ & $0.350 \mathrm{E}-01$ & in/in \\
\hline eps $\mathrm{mS}$ & $0.500 \mathrm{E}-01$ & in/in \\
\hline eps mTOR & $0.500 \mathrm{E}-01$ & in/in \\
\hline kv & $0.225 E+00$ & BTU-in/hr \\
\hline Tgdr & $0.740 \mathrm{E}+03$ & $\mathrm{~F}$ \\
\hline \multicolumn{3}{|l|}{ ss } \\
\hline Tgmax & $0.115 \mathrm{E}+04$ & $\mathrm{~F}$ \\
\hline Cal & $0.000 \mathrm{E}+00$ & non-dim \\
\hline nal & $1.000 \mathrm{E}+00$ & non-dim \\
\hline $\mathrm{D}$ & $0.000 \mathrm{E}+00$ & non-dim \\
\hline DE1 & $0.000 \mathrm{E}+00$ & non-dim \\
\hline $\mathrm{nEl}$ & $1.000 \mathrm{E}+00$ & non-dim \\
\hline DE2 & $-.100 \mathrm{E}+01$ & non-dim \\
\hline $\mathrm{nE2}$ & $1.000 E+00$ & non-dim \\
\hline DS1 & $0.000 \mathrm{E}+00$ & non-dim \\
\hline $\mathrm{nS} 1$ & $1.000 \mathrm{E}+00$ & non-dim \\
\hline DS2 & $-.100 \mathrm{E}+01$ & non-dim \\
\hline $\mathrm{nS2}$ & $1.000 \mathrm{E}+00$ & non-dim \\
\hline Dalf1 & $0.000 \mathrm{E}+00$ & non-dim \\
\hline nalf1 & $1.000 \mathrm{E}+00$ & non-dim \\
\hline Dalf2 & $-.100 \mathrm{E}+01$ & non-dim \\
\hline nalf2 & $1.000 \mathrm{E}+00$ & non-dim \\
\hline
\end{tabular}




\subsection{Appendix E \\ Output File}

The following pages contain an abbreviated version of an output from the ICAN code run by using the input file in appendix $\mathrm{C}$ and the material file in appendix D. Omitted material, which is unchanged from the original ICAN, is indicated by three stars, i.e., ***.
Editorial comments added to the new output are in bold between angles

«LIKE THIS $\gg \gg$

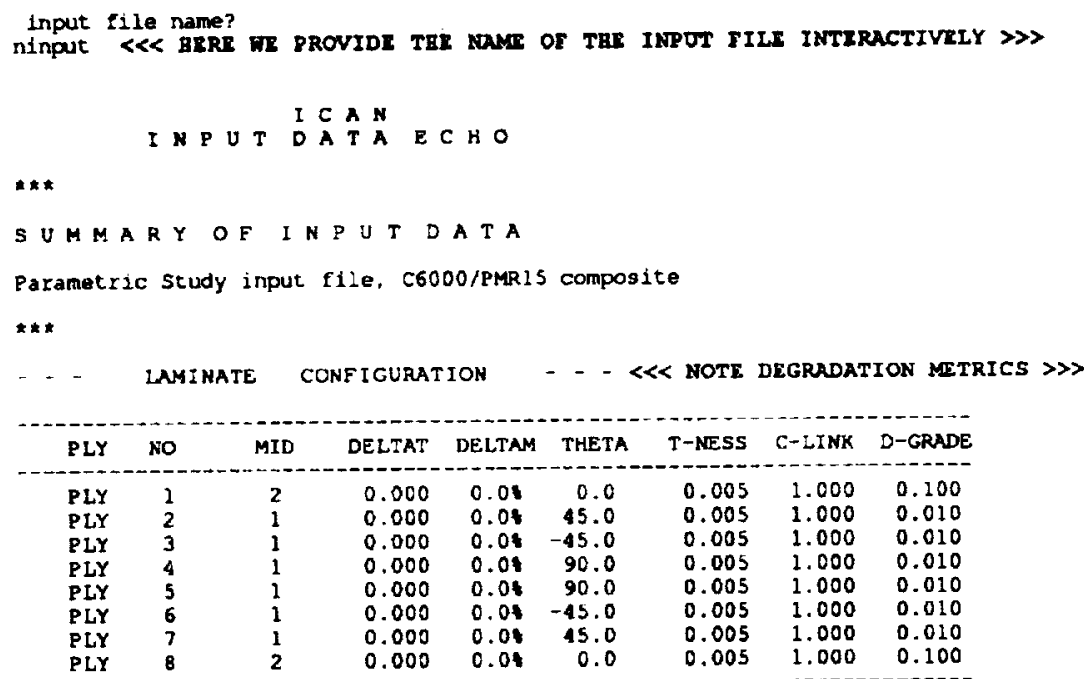

\begin{tabular}{lllllllll} 
PLY & NO & MID & DELTAT & DELTAM & THETA & T-NESS & C-LINK & D-GRADE \\
\hline PLY & 1 & 2 & 0.000 & 0.0 & 0.0 & 0.005 & 1.000 & 0.100 \\
PLY & 2 & 1 & 0.000 & 0.04 & 45.0 & 0.005 & 1.000 & 0.010 \\
PLY & 3 & 1 & 0.000 & 0.07 & -45.0 & 0.005 & 1.000 & 0.010 \\
PLY & 4 & 1 & 0.000 & 0.04 & 90.0 & 0.005 & 1.000 & 0.010 \\
PLY & 5 & 1 & 0.000 & 0.04 & 90.0 & 0.005 & 1.000 & 0.010 \\
PLY & 6 & 1 & 0.000 & 0.01 & -45.0 & 0.005 & 1.000 & 0.010 \\
PLY & 7 & 1 & 0.000 & 0.08 & 15.0 & 0.005 & 1.000 & 0.010 \\
PLY & 8 & 2 & 0.000 & 0.04 & 0.0 & 0.005 & 1.000 & 0.100
\end{tabular}

$* *$

$\rightarrow$ CONSTITUENT PROPERTIES: ECHO FROM DATA BANK. $<--$

PRIMARY FIBER PROPERTIES:C-6K FIBER

$\begin{array}{rllr}1 & \text { ELASTIC MODULI } & \text { EFPI } & 0.3400 E+08 \\ 2 & & \text { EFP2 } & 0.2200 E+07 \\ 3 & \text { SHEAR MODULI } & \text { GFP12 } & 0.5400 E+07 \\ 4 & & \text { GFP23 } & 0.1100 E+07 \\ 5 & \text { POISSON"S RATIO } & \text { NUFP12 } & 0.2200 E+00 \\ 6 & & \text { NUFP23 } & 0.2500 E+00 \\ 7 & \text { THERM. EXP. COEF. } & \text { CTEFP1 } & -0.5900 E-06 \\ 8 & & \text { CTEFP2 } & 0.5600 E-05 \\ 9 & \text { DENSITY } & \text { RHOFP } & 0.6400 E-01 \\ 10 & \text { NO. OF FIBERS/END } & \text { NFP } & 0.1000 E+01 \\ 11 & \text { FIBER DIANETER } & \text { DIFP } & 0.2800 E-03 \\ 12 & \text { HEAT CAPACITY } & \text { CFPC } & 0.1660 E+00 \\ 13 & \text { HEAT CONDUCTIVITY } & \text { KFP1 } & 0.4400 E+01 \\ 14 & & \text { KFP2 } & 0.4400 E+00 \\ 15 & & \text { KFP3 } & 0.4400 E+00 \\ 16 & \text { STRENGTHS } & \text { SFPT } & 0.5500 E+06 \\ 17 & & \text { SFPC } & 0.6500 E+06\end{array}$

《 HER WE COMPUTI THE DEGRADED PROPERTIES. NOTE ECHO OF DEGRADATION CONSTANTS $\gg>$

PRIMARY MATRIX PROPERTIES; PMHM MATRIX. DRY RT. PROPERTIES.

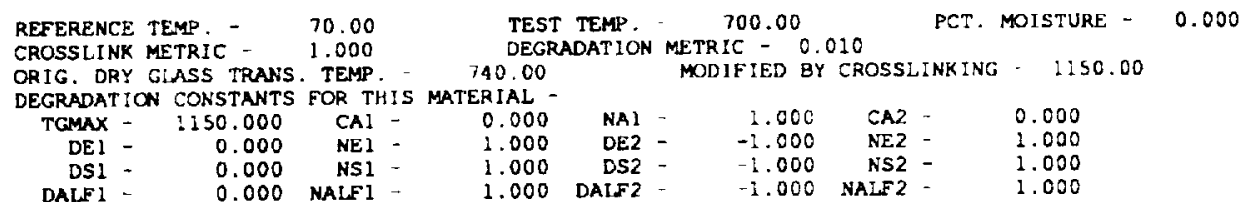

ORIGINAL MATRIX PROPERTIES

$\begin{array}{llll}1 & \text { ELASTIC NODUWS } & \text { EMP } & 0.4700 E+06 \\ 2 & \text { SHEAR MODULUS } & \text { GMP } & 0.1728 \mathrm{E}+06 \\ 3 & \text { POISSON'S RATIC } & \text { NUMP } & 0.3600 E+00 \\ 4 & \text { THERM. EXP. COEF. } & \text { CTEMP } & 0.2800 E-06 \\ 5 & \text { DENSITY } & \text { RHGP } & 0.4400 E-01 \\ 6 & \text { HEAT CAPACITY } & \text { CMPC } & 0.2500 E+00 \\ 7 & \text { HEAT CONDUCTIVITY } & \text { KOPP } & 0.1460 E+00\end{array}$

NEW PROPERTIES: CHANGED BECAUSE MEW EROERTIES: CHANGED BECAUSE 


$\begin{array}{rllllll}8 & \text { STRENGTHS } & \text { SMPT } & 0.8100 E+04 & * & \text { NEW SMPT } & 0.5176 E+04 \\ 9 & & \text { SMPC } & 0.1650 E+05 & * & \text { NEW SMPC } & 0.1054 E+05 \\ 10 & & \text { SMPS } & 0.1350 E+05 & \text { NEW SMPS } & 0.8627 E+04 \\ 11 & \text { MOISTURE COEF } & \text { BTAMP } & 0.4000 E-02 & * & \text { NEW BTAP } & 0.4000 E-02 \\ 12 & \text { DIFFUSIVITY } & \text { DIFMP } & 0.2000 E-03 & \text { NEW DIFMP } & 0.2000 E-03\end{array}$

*** « A LARGE MOONT OF OUTPUT OUITTED HERE- DEGRADED PROPERTIIS FOR MATIRIAL 2, COMPOSITE PROPERTIES, AND THR STRESS CALCULATIONS FROM TAR ORIGINAL ICAN (HEICB INCLUDE DEGRADATION-INDOCED CBANGES IN TRE MATERIAL PROPERTIRS, BUT NOT THE ETFECTS OF MATERIAL SARIARAGR) $>>$

$\ll$ MON WE OOTPOT LAMINATE DISPLACEMRNTS AND PLY STRESSES DOE SOLEY TO DRGRADATION $\gg>$

LAMINATE DISPLACEMENT-FORCE RELATIONS SOLELY DUE TO EFFECTS OF MATRIX DEGRADATION

DISP.

DISPLACEMENT FORCE RELATIONS

DEGRAD. FORCES

$\begin{array}{rrrrrrrr} & -1- & -2- & -3- & -4- & -5- & -6- \\ -0.1836 E-03 & 0.3131 E-05 & -0.9951 E-06 & -0.8044 E-13 & 0.1007 E-10 & -0.1153 E-10 & -0.3427 E-11 & -0.9797 E+02 \\ -0.2906 E-03 & -0.9951 E-06 & 0.3135 E-05 & 0.2534 E-12 & -0.4668 E-11 & 0.1066 E-10 & -0.6329 E-11 & -0.1238 E+03 \\ -0.2485 E-10 & -0.8044 E-13 & 0.2534 E-12 & 0.8277 E-05 & -0.1819 E-12 & -0.2127 E-11 & -0.3200 E-10 & -0.1642 E-06 \\ 0.2594 E-09 & 0.1007 E-10 & -0.4668 E-11 & -0.1819 E-12 & 0.1138 E-01 & -0.7273 E-02 & -0.1596 E-02 & 0.6786 E-07 \\ 0.9368 E-10 & -0.1153 E-10 & 0.1066 E-10 & -0.2127 E-11 & -0.7273 E-02 & 0.5534 E-01 & -0.1866 E-01 & 0.1423 E-37 \\ 0.7861 E-09 & -0.3427 E-11 & -0.6329 E-11 & -0.3200 E-10 & -0.1596 E-02 & -0.1866 E-01 & 0.6915 E-01 & 0.5898 E-09\end{array}$

NOTE: THE DISPLACEMENTS ARE REFERENCE P:ANE MEMBRANE STRAINS (UX, VY, VXPUY) AND CURVATURES (WXX . WYY . WXY)

PLY STRESSES, STRAINS, AND MAX. STRESS CRITERIA FAILURE RATIOS

DUE SOLELY TO DEGRADATION EFFECTS

IN PLY (MATERIAL) COORDINATE SYSTEM

\begin{tabular}{|c|c|c|c|c|c|c|c|c|c|}
\hline$L Y$ & SIGII & $S I G 22$ & SIGI2 & EPS1: & EPS22 & EPS12 & SRII & $S R 22$ & SR 12 \\
\hline $\begin{array}{l}1 \\
2 \\
3 \\
4 \\
5 \\
6 \\
7 \\
8\end{array}$ & $\begin{array}{r}2.590 \mathrm{E}+03 \\
-4.093 \mathrm{E}+03 \\
-4.093 \mathrm{E}+03 \\
-5.145 \mathrm{E}+03 \\
-5.145 \mathrm{E}+03 \\
-4.093 \mathrm{E}+03 \\
-4.093 \mathrm{E}+03 \\
2.590 \mathrm{E}+03\end{array}$ & $\begin{array}{l}8.643 E+03 \\
6.882 E+02 \\
6.882 E+02 \\
7.221 E+02 \\
7.221 E+02 \\
6.882 E+02 \\
6.882 E+02 \\
8.643 E+03\end{array}$ & $\begin{array}{r}-3.861 \mathrm{E}-06 \\
-4.650 \mathrm{E}+01 \\
4.650 \mathrm{E}+01 \\
1.393 \mathrm{E}-05 \\
1.581 \mathrm{E}-05 \\
4.650 \mathrm{E}+01 \\
-4.650 \mathrm{E}+01 \\
-1.589 \mathrm{E}-05\end{array}$ & $\begin{array}{l}-1.836 E-04 \\
-2.371 E-04 \\
-2.371 E-04 \\
-2.906 E-04 \\
-2.906 E-04 \\
-2.371 E-04 \\
-2.371 E-04 \\
-1.836 E-04\end{array}$ & $\begin{array}{l}-2.906 E-04 \\
-2.371 E-04 \\
-2.371 E-04 \\
-1.836 E-04 \\
-1.836 E-04 \\
-2.371 E-04 \\
-2.371 E-04 \\
-2.906 E-04\end{array}$ & $\begin{array}{r}-9.717 \mathrm{E}-12 \\
-1.070 \mathrm{E}-04 \\
1.070 \mathrm{E}-04 \\
3.204 \mathrm{E}-11 \\
3.636 \mathrm{E}-11 \\
1.070 \mathrm{E}-04 \\
-1.070 \mathrm{E}-04 \\
-3.998 \mathrm{E}-11\end{array}$ & $\begin{array}{l}0.0081 \\
0.0497 \\
0.0497 \\
0.0624 \\
0.0624 \\
0.0497 \\
0.0497 \\
0.0081\end{array}$ & $\begin{array}{l}2.2227 \\
0.1605 \\
0.1605 \\
0.1684 \\
0.1684 \\
0.1605 \\
0.2605 \\
2.2227\end{array}$ & $\begin{array}{l}0.0000 \\
0.0067 \\
0.0067 \\
0.0000 \\
0.0000 \\
0.0067 \\
0.0067 \\
0.0000\end{array}$ \\
\hline
\end{tabular}

« NOW (FINALLY) WE OUTPOT THE DISPLACEMENTS AND STRESSES DUE TO THE ENTIRE LOADING CASE SPECIFIEDMICHANICAL, THERMAL, GYGRAL, AND DEGRADATION INDUCED $\gg$

LAMINATE DISPLACEMENT-FORCE RELATIONS INCLUDING ALL LOADING EFFECTS

DISP. DISPIACEMENT FORCE RELATIONS

COMB:NED FORCES

\begin{tabular}{|c|c|c|c|c|c|c|c|c|}
\hline $\begin{array}{l}1 \\
2 \\
3 \\
4 \\
5\end{array}$ & $\begin{array}{r}0.2948 E-02 \\
-0.1286 E-02 \\
-0.1053 E-09 \\
0.1033 E-07 \\
-0.1144 E-07 \\
-0.2641 E-08\end{array}$ & $\begin{array}{r}-1 \\
0.3131 \mathrm{E}-05 \\
-0.9951 \mathrm{E}-06 \\
-0.8044 \mathrm{E}-13 \\
0.1007 \mathrm{E}-10 \\
-0.1153 \mathrm{E}-10 \\
-0.3427 \mathrm{E}-11\end{array}$ & $\begin{array}{r}-2- \\
0.9951 \mathrm{E}-06 \\
0.3135 \mathrm{E}-05 \\
0.2534 \mathrm{E}-12 \\
-0.4668 \mathrm{E}-11 \\
0.1066 \mathrm{E}-10 \\
-0.6329 \mathrm{E}-11\end{array}$ & $\begin{array}{r}-3 \\
-0.8044 E-13 \\
0.2534 E-12 \\
0.8277 E-05 \\
-0.2819 E-12 \\
-0.2127 E-11 \\
-0.3200 E-10\end{array}$ & $\begin{array}{r}-4- \\
0.1007 \mathrm{E}-10 \\
-0.4668 \mathrm{E}-11 \\
-0.1819 \mathrm{E}-12 \\
0.1138 \mathrm{E}-01 \\
-0.7273 \mathrm{E}-02 \\
-0.1596 \mathrm{E}-02\end{array}$ & $\begin{array}{r}-5- \\
-0.1153 E-10 \\
0.1066 \mathrm{E}-10 \\
-0.2127 \mathrm{E}-11 \\
-0.7273 \mathrm{E}-02 \\
0.5534 \mathrm{E}-01 \\
-0.1866 \mathrm{E}-01\end{array}$ & $\begin{array}{c}-6- \\
-0.3427 \mathrm{E}-11 \\
-0.6329 \mathrm{E}-11 \\
-0.3200 \mathrm{E}-10 \\
-0.1596 \mathrm{E}-02 \\
-0.1866 \mathrm{E}-01 \\
0.6915 \mathrm{E}-01\end{array}$ & $\begin{array}{r}0.9020 E+03 \\
-0.1238 E+03 \\
-0.1642 E-06 \\
0.6786 E-07 \\
0.1423 E-07 \\
0.5898 E-09\end{array}$ \\
\hline
\end{tabular}

NOTE: THE DISPLACEMENTS ARE REFERENCE PLANE MEMBRANE STRAINS (UX, VY , VXPUY) AND CURVATURES (WXX, WYY, WXY)

PLY STRESSES, STRAINS, AND MAX. STRESS CRITERIA FAILURE RATIOS

INCLUDING EFFECTS OF MECHAN CAL LOAD, TEMPERATURE, MOISTURE, AND DEGRADAT:ON IN PLY (MATERIAL) COORDINATE SYSTEM

\begin{tabular}{|c|c|c|c|c|c|c|c|c|c|}
\hline PLY & sigll & SIG22 & SIGI2 & EPSI: & EPS22 & EPS 12 & SRII & $\mathrm{SR} 22$ & SR:2 \\
\hline $\begin{array}{l}1 \\
2 \\
3 \\
4 \\
5 \\
6 \\
7 \\
8\end{array}$ & $\begin{array}{r}6.467 \mathrm{E}+04 \\
1.744 \mathrm{E}+04 \\
1.744 \mathrm{E}+04 \\
-2.419 \mathrm{E}+04 \\
-2.419 \mathrm{E}+04 \\
1.744 \mathrm{E}+04 \\
1.744 \mathrm{E}+04 \\
6.467 \mathrm{E}+04\end{array}$ & $\begin{array}{l}9.542 E+03 \\
1.890 \mathrm{E}+03 \\
1.890 \mathrm{E}+03 \\
3.234 \mathrm{E}+03 \\
3.234 \mathrm{E}+03 \\
1.890 \mathrm{E}+03 \\
1.890 \mathrm{E}+03 \\
9.542 \mathrm{E}+03\end{array}$ & $\begin{array}{r}-6.204 E-05 \\
-1.840 \mathrm{E}+03 \\
1.840 \mathrm{E}+03 \\
2.098 \mathrm{E}-04 \\
2.03 \mathrm{SE}-04 \\
1.840 \mathrm{E}+03 \\
-1.840 \mathrm{E}+03 \\
-2.163 \mathrm{E}-0 \mathrm{~S}\end{array}$ & $\begin{array}{r}2.948 \mathrm{E}-03 \\
8.311 \mathrm{E}-04 \\
8.311 \mathrm{E}-04 \\
-.286 \mathrm{E}-03 \\
-.286 \mathrm{E}-03 \\
8.311 \mathrm{E}-04 \\
8.311 \mathrm{E}-04 \\
2.948 \mathrm{E}-03\end{array}$ & $\begin{array}{r}-1.286 \mathrm{E}-03 \\
\text { B.311E-04 } \\
8.311 \mathrm{E}-04 \\
2.948 \mathrm{E}-03 \\
2.948 \mathrm{E}-03 \\
\text { B.311E-04 } \\
\text { 8.311E-04 } \\
-1.286 \mathrm{E}-03\end{array}$ & $\begin{array}{r}-1.561 E-10 \\
-4.233 E-03 \\
4.233 E-03 \\
4.826 E-10 \\
4.681 E-10 \\
4.233 E-03 \\
-4.233 E-03 \\
5.444 E-11\end{array}$ & $\begin{array}{l}0.2027 \\
0.0547 \\
0.0547 \\
0.2936 \\
0.2936 \\
0.0547 \\
0.0547 \\
0.2027\end{array}$ & $\begin{array}{l}2.1968 \\
0.4408 \\
0.4408 \\
0.7541 \\
0.7541 \\
0.4408 \\
0.4408 \\
2.1968\end{array}$ & $\begin{array}{l}0.0000 \\
0.2640 \\
0.2640 \\
0.0000 \\
0.0000 \\
0.2640 \\
0.2640 \\
0.0000\end{array}$ \\
\hline
\end{tabular}

« NOTE TRANSYRRSE STRESS RATIO IN THE OOTER PLIES (SR22) IS > 1, INDICATING CRACKING 》>

«

COMBINED UITA THE IFTECTS OF DEGRADATION INDUCED PLY STRESSES. TO GIT TOTAL MICROSTRESSES,

YOD NOST COMBINE TAESE WITA THE OTHER MICROSTRESSES CALCULALATED BY THE OLOER ROUTINES IN ICAN $\gg$ 
MTCROSTRESSES IN PRIMARY AND SECONDARY CCNPOSITES

DUE SOLELY TO DEGRADATION EFFECTS (NOT INCLUDING PLY STRESSES)

PRIMARY VALUES ON FIRST LINE, SECONDARY (IF ANY) FOLLONS

\begin{tabular}{|c|c|c|c|c|c|c|c|c|c|c|}
\hline PLY & SM? I & SF 11 & SM22A & $5 H 22 B$ & SF 22 & $\sin 33 A$ & SM33B & SF 33 & SINCN & sincs \\
\hline $\begin{array}{l}1 \\
2 \\
3 \\
4 \\
5 \\
6 \\
7 \\
8\end{array}$ & $\begin{array}{l}9.049 E+03 \\
9.948 E+02 \\
9.948 E+02 \\
9.948 E+02 \\
9.948 E+02 \\
9.948 E+02 \\
9.948 E+02 \\
9.049 E+03\end{array}$ & $\begin{array}{l}-6.551 E+03 \\
-7.202 E+02 \\
-7.202 E+02 \\
-7.202 E+02 \\
-7.202 E+02 \\
-7.202 E+02 \\
-7.202 E+02 \\
-6.551 E+03\end{array}$ & $\begin{array}{l}6.154 \mathrm{E}+03 \\
6.770 \mathrm{E}+02 \\
6.770 \mathrm{E}+02 \\
6.770 \mathrm{E}+02 \\
6.770 \mathrm{E}+02 \\
6.770 \mathrm{E}+02 \\
6.770 \mathrm{E}+02 \\
6.154 \mathrm{E}+03\end{array}$ & $\begin{array}{l}-1.927 \mathrm{E}+03 \\
-2.120 \mathrm{E}+02 \\
-2.120 \mathrm{E}+02 \\
-2.120 \mathrm{E}+02 \\
-2.120 \mathrm{E}+02 \\
-2.120 \mathrm{E}+02 \\
-2.120 \mathrm{E}+02 \\
-1.927 \mathrm{E}+03\end{array}$ & $\begin{array}{l}-1.927 \mathrm{E}+03 \\
-2.120 \mathrm{0}+02 \\
-2.120 \mathrm{0}+02 \\
-2.120 \mathrm{E}+02 \\
-2.120 \mathrm{0}+02 \\
-2.120 \mathrm{E}+02 \\
-2.120 \mathrm{0}+02 \\
-1.927 \mathrm{E}+03\end{array}$ & $\begin{array}{l}6.154 \mathrm{E}+03 \\
6.770 \mathrm{E}+02 \\
6.770 \mathrm{E}+02 \\
6.770 \mathrm{E}+02 \\
6.770 \mathrm{E}+02 \\
6.770 \mathrm{E}+02 \\
6.770 \mathrm{E}+02 \\
6.154 \mathrm{E}+03\end{array}$ & $\begin{array}{l}-1.927 \mathrm{E}+03 \\
-2.120 \mathrm{E}+02 \\
-2.120 \mathrm{0}+02 \\
-2.120 \mathrm{E}+02 \\
-2.120 \mathrm{0}+02 \\
-2.120 \mathrm{E}+02 \\
-2.120 \mathrm{E}+02 \\
-1.927 \mathrm{E}+03\end{array}$ & $\begin{array}{l}-1.927 \mathrm{E}+03 \\
-2.120 \mathrm{O}+02 \\
-2.120 \mathrm{O}+02 \\
-2.120 \mathrm{0}+02 \\
-2.120 \mathrm{E}+02 \\
-2.120 \mathrm{E}+02 \\
-2.120 \mathrm{O}+02 \\
-1.927 \mathrm{E}+03\end{array}$ & $\begin{array}{l}5.977 E+03 \\
6.576 E+02 \\
6.576 E+02 \\
6.576 E+02 \\
6.576 E+02 \\
6.576 E+02 \\
6.576 E+02 \\
5.977 E+03\end{array}$ & $\begin{array}{l}0.000 \mathrm{E}+00 \\
0.000 \mathrm{E}+00 \\
0.000 \mathrm{D}+00 \\
0.000 \mathrm{0}+00 \\
0.000 \mathrm{E}+00 \\
0.000 \mathrm{E}+00 \\
0.000 \mathrm{E}+00 \\
0.000 \mathrm{0}+00\end{array}$ \\
\hline
\end{tabular}

MICROSTRESSES IN PRIMARY AND SECONDARY COMPOSTTES

DUE TO DEGRADATION EFFECTS, INCLUDING PLY STRESSES

PRIMARY VALUES ON FIRST LINE, SECONDARY (IF ANY) FOLIONS

\begin{tabular}{|c|c|c|c|c|c|c|c|c|c|c|}
\hline PLY & SHI 1 & SFI1 & SM22A & SM22B & SF22 & $5 M 33 A$ & SMI3B & SF 33 & SIMCN & SINCS \\
\hline $\begin{array}{l}1 \\
2 \\
3 \\
4 \\
5 \\
6 \\
7 \\
8\end{array}$ & $\begin{array}{l}9.126 \mathrm{E}+03 \\
9.365 \mathrm{E}+02 \\
9.365 \mathrm{E}+02 \\
9.207 \mathrm{E}+02 \\
9.207 \mathrm{E}+02 \\
9.365 \mathrm{E}+02 \\
9.365 \mathrm{E}+02 \\
9.126 \mathrm{E}+03\end{array}$ & $\begin{array}{l}-2.072 \mathrm{E}+03 \\
-7.730 \mathrm{E}+03 \\
-7.730 \mathrm{E}+03 \\
-9.533 \mathrm{E}+03 \\
-9.533 \mathrm{E}+03 \\
-7.730 \mathrm{E}+03 \\
-7.730 \mathrm{E}+03 \\
-2.072 \mathrm{E}+03\end{array}$ & $\begin{array}{l}9.579 E+03 \\
9.515 E+02 \\
9.515 E+02 \\
9.640 E+02 \\
9.640 E+02 \\
9.515 E+02 \\
9.515 E+02 \\
9.579 E+03\end{array}$ & $\begin{array}{l}8.349 E+03 \\
6.057 E+02 \\
6.057 E+02 \\
6.464 E+02 \\
6.464 E+02 \\
6.057 \mathrm{E}+02 \\
6.057 \mathrm{E}+02 \\
6.349 \mathrm{E}+03\end{array}$ & $\begin{array}{l}8.349 E+03 \\
6.057 E+02 \\
6.057 E+02 \\
6.464 E+02 \\
6.464 E+02 \\
6.057 E+02 \\
6.057 E+02 \\
8.349 E+03\end{array}$ & $\begin{array}{l}5.920 E+03 \\
6.526 \mathrm{E}+02 \\
6.526 \mathrm{E}+02 \\
6.504 \mathrm{E}+02 \\
6.504 \mathrm{E}+02 \\
6.526 \mathrm{E}+02 \\
6.526 \mathrm{E}+02 \\
5.920 \mathrm{0}+03\end{array}$ & $\begin{array}{l}-1.854 E+03 \\
-2.044 E+02 \\
-2.044 E+02 \\
-2.037 E+02 \\
-2.037 E+02 \\
-2.044 E+02 \\
-2.044 E+02 \\
-1.854 E+03\end{array}$ & $\begin{array}{l}-1.054 E+03 \\
-2.044 E+02 \\
-2.044 E+02 \\
-2.037 E+02 \\
-2.037 E+02 \\
-2.044 E+02 \\
-2.044 E+02 \\
-1.054 E+03\end{array}$ & $\begin{array}{l}1.555 E+04 \\
1.410 E+03 \\
1.418 E+03 \\
1.454 E+03 \\
1.454 E+03 \\
1.418 E+03 \\
1.418 E+03 \\
1.555 E+04\end{array}$ & $\begin{array}{l}-9.801 E+03 \\
-7.840 E+02 \\
-7.840 E+02 \\
-8.227 E+02 \\
-8.227 E+02 \\
-7.840 E+02 \\
-7.840 E+02 \\
-9.801 E+03\end{array}$ \\
\hline & & & & & & & & & & \\
\hline
\end{tabular}




\section{References}

1. Meador, M.A.; Cavano, P.J.; and Malaric, D.C.: High Temperature Polymer Matrix Composites for Extreme Environments. Proceedings of the Sixth Annual ASM/ESD Advanced Composites Conference, 1990, pp. 529-539.

2. Vannucci, R.D.; and Cifani, D.: $700^{\circ} \mathrm{F}$ Properties of Autoclave Cured PMR-II Composites. Proceedings of the 20th International SAMPE Technical Conference, 1988, pp. 562-575.

3. Pederson, C.L., et al.: The Effect of Isothermal Aging on Transverse Crack Development in Carbon Fiber Reinforced Cross-Ply Laminates. CCM Report 93-42, University of Delaware Center for Composite Materials, Newark, DE, Nov. 1993.

4. Pederson, C.L.: The Effect of Temperature on Transverse Cracking in High Performance Composites. CCM Repor 92-28, University of Delaware Center for Composite Materials, Newark, DE, June 1992.

5. Gates, T.S.; and Brinson, L.C.: Acceleration of Aging in Graphite/ Bismaleimide and Graphite/Thermoplastic Composites. AIAA Paper 94-1582-CP, April 1994, pp. 2096-2105.

6. Bowles, K.J.: Thermo-Oxidative Stability Studies of PMR-15 Polymer Matrix Composites Reinforced with Various Continuous Fibers. SAMPE Quarterly, vol. 21, no. 4, July 1990, pp. 6-13.

7. Bowles, K.J.; Jayne, D.; and Leonhardt, T.A.: Isothermal Aging Effects on PMR-15 Resin. SAMPE Quarterly, vol. 24, no. 2, 1993, pp. 2-9.

8. Bowles, K.J.; and Nowak, G.: Thermo-Oxidative Stability Studies of Celion 6000/PMR-15 Unidirectional Composites, PMR-15, and Celion 6000 Fiber. J. Compos. Mater., vol. 22, 1988, pp. 966-985.
9. Bowles, K J.: A Thermally Modified Polymer Matrix Composite Material With Structural Integrity to $371^{\circ} \mathrm{C}$. Proceedings of the $20 \mathrm{~h}$ International SAMPE Conference, 1988, pp. 552-561. (NASA TM-100922).

10. Martin, R.H.; Siochi, E.J.; and Gates, T.S.: Isothermal Aging of IM7/8320 and IM7/5260. Proceedings of the American Society for Composites Seventh Technical Conference on Composite Materials, Mechanics, and Processing. 1992, pp. 207-217.

11. Murthy, P.L.N.; Ginty, C.A.; and Sanfeliz, J.G.: Second Generation Integrated Composite Analyzer (ICAN) Computer Code. NASA TP-3290, 1993.

12. Chamis, C.C.: Simplified Composite Micromechanics Equations for Hygral, Thermal, and Mechanical Properties, SAMPE Quarterly, vol. 15, Apr. 1984, pp. 14-23.

13. Chamis, C.C.: Simplified Composite Micromechanics for Predicting Microstresses. NASA TM-87295, 1986.

14. Chamis, C.C.; and Ginty, C.A.: Fiber Composite Structural Durability and Damage Tolerance: Simplified Predictive Methods. NASA TM-100179, 1987.

15. Jones, R.M.: Mechanics of Composite Materials. Hemisphere. New York, 1975.

16. Bowles, K.J.: Transverse Flexural Tests as a Tool for Assessing Damage to PMR-15 Composites from Isothermal Aging in Air at Elevated Temperatures. SAMPE Quarterly, vol. 24, no. 2, 1993, pp. 49-53. 
Public reporting burden for this collection of information is estimated to average 1 hour per response, including the tine for reviewing inatructions, searching existing deta sources, gathering and mantaining the dats needed, and comploting and reviewing the colloction of intomation. Send comments regarding this burden etions and Peports. 1215 Jefferson coilection

\begin{tabular}{|l|l|l|}
\hline 1. AGENCY USE ONLY (Leave blank) & $\begin{array}{c}\text { 2. REPORT DATE } \\
\text { January } 1996\end{array}$ & $\begin{array}{r}\text { 3. REPORT TYPE AND DATES COVERED } \\
\text { Technical Memorandum }\end{array}$
\end{tabular}

\section{TTTLE AND SUBTTTLE}

Stress and Damage in Polymer Matrix Composite Materials Due to Material

Degradation at High Temperatures
5. FUNDING NUMBERS

$$
\text { WU-505-62-10 }
$$

Hugh L. McManus and Christos C. Chamis

\section{PERFORMING ORGANIZATION NAME(S) AND ADDRESS(ES)}

National Aeronautics and Space Administration

Lewis Research Center

Cleveland, Ohio 44135-3191

8. PERforining Opganization REPORT NUMBER

E-9506

9. SPONSORINGMONITORING AGENCY NAME(S) AND ADDRESS(ES)

10. SPONSORINGMONITORING AGENCY REPORT NUMBER

National Aeronautics and Space Administration

Washington, D.C. 20546-0001

NASA TM-4682

\section{SUPPLEMENTARY NOTES}

Hugh L. McManus, Massachusetts Institute of Technology, Cambridge, Massachusetts 02139 and Summer Faculty Fellow at NASA Lewis Research Center, 1993; Christos C. Chamis, NASA Lewis Research Center. Responsible person, Christos C. Chamis, organization code 5200, (216) 433-3252.

12a. DISTRIBUTIONAVAILABILITY STATEMENT

12b. DISTRIBUTION CODE

Unclassified - Unlimited

Subject Category 24

This publication is available from the NASA Center for Aerospace Information, (301) 621-0390.

13. ABSTRACT (Maximum 200 words)

This report describes analytical methods for calculating stresses and damage caused by degradation of the matrix constituent in polymer matrix composite materials. Laminate geometry, material properties, and matrix degradation states are specified as functions of position and time. Matrix shrinkage and property changes are modeled as functions of the degradation states. The model is incorporated into an existing composite mechanics computer code. Stresses, strains, and deformations at the laminate, ply, and micro levels are calculated, and from these calculations it is determined if there is failure of any kind. The rationale for the model (based on published experimental work) is presented, its integration into the laminate analysis code is outlined, and example results are given, with comparisons to existing material and structural data. The mechanisms behind the changes in properties and in surface cracking during long-term aging of polyimide matrix composites are clarified. High-temperature-material test methods are also evaluated.

14. SUBJECT TERMS

15. NUMBER OF PAGES 27

Fibers; Shrinkage; Oxidation; Micro; Ply; Laminate; Failure; Surface cracking; Long term; Best methods; Equations; Predictions; Comparisons

17. SECUAITY CLASSIFICATION OF REPORT Unclassified
18. SECURITY CLASSIFICATION OF THIS PAGE Unclassified
19. SECUATTY CLASSIFICATION OF ABSTRACT Unclassified
16. PRICE CODE A03 

National Aeronautics and

Space Administration

Lewis Research Center

21000 Brookpark Rd.

Cleveland, OH 44135-3191

Official Business

Penalty lor Privalo Use $\$ 300$

POSTMASTER: If Undeliverable - Do Not Return 